\title{
Calcium, Calpain, and Calcineurin in Low-Frequency Depression of Transmitter Release
}

\author{
Lorelei B. Silverman-Gavrila, ${ }^{1}$ Moshe Praver, ${ }^{1}$ Donald L. Mykles, ${ }^{2}$ and Milton P. Charlton ${ }^{1}$ \\ ${ }^{1}$ Department of Physiology, University of Toronto, Toronto, Ontario, Canada M5S 1A8, and ${ }^{2}$ Department of Biology, Colorado State University, Fort Collins, \\ Colorado 80523
}

Low-frequency depression (LFD) of transmitter release occurs at phasic synapses with stimulation at $0.2 \mathrm{~Hz}$ in both isolated crayfish (Procambarus clarkii) neuromuscular junction (NMJ) preparations and in intact animals. LFD is regulated by presynaptic activity of the $\mathrm{Ca}^{2+}$-dependent phosphatase calcineurin (Silverman-Gavrila and Charlton, 2009). Since the fast $\mathrm{Ca}^{2+}$ chelator BAPTA-AM inhibits LFD but the slow chelator EGTA-AM does not, the $\mathrm{Ca}^{2+}$ sensor for LFD may be close to a $\mathrm{Ca}^{2+}$ source at active zones. Calcineurin can be activated by the $\mathrm{Ca}^{2+}$-activated protease calpain, and immunostaining showed that both proteins are present at nerve terminals. Three calpain inhibitors, calpain inhibitor I, MDL-28170, and PD150606, but not the control compound PD145305, inhibit LFD both in the intact animal as shown by electromyograms and by intracellular recordings at neuromuscular junctions. Analysis of mini-EPSPs indicated that these inhibitors had minimal postsynaptic effects. Proteolytic activity in CNS extract, detected by a fluorescent calpain substrate, was modulated by $\mathrm{Ca}^{2+}$ and calpain inhibitors. Western blot analysis of CNS extract showed that proteolysis of calcineurin to a fragment consistent with the constitutively active form required $\mathrm{Ca}^{2+}$ and was blocked by calpain inhibitors. Inhibition of LFD by calpain inhibition blocks the reduction in phosphoactin and the depolymerization of tubulin that normally occurs in LFD, probably by blocking the dephosphorylation of cytoskeletal proteins by calcineurin. In contrast, high-frequency depression does not involve protein phosphorylation- or calpain-dependent mechanisms. LFD may involve a specific pathway in which local $\mathrm{Ca}^{2+}$ signaling activates presynaptic calpain and calcineurin at active zones and causes changes of tubulin cytoskeleton.

\section{Introduction}

Modulation of synaptic transmission is an important feature of neural function and is involved in several types of cellular learning. Many types of cellular learning involve changes in phosphorylation of synaptic proteins. For instance, cerebellar (Jouvenceau and Dutar, 2006) and hippocampal mammalian long-term depression (LTD) (Yasuda et al., 2003) involve presynaptic and postsynaptic activity of the $\mathrm{Ca}^{2+} /$ calmodulin-activated protein phosphatase 3 (PP3, formally $2 \mathrm{~B}$, calcineurin).

We recently described another type of synaptic depression, low-frequency depression (LFD) of transmitter release, at crayfish phasic synapses that is caused by stimulation at $0.2 \mathrm{~Hz}$ and

Received June 28, 2012; revised Oct. 23, 2012; accepted Nov. 19, 2012.

Author contributions: L.B.S.-G. and M.P.C. designed research; L.B.S.-G. and M.P. performed research; D.L.M. contributed unpublished reagents/analytic tools; L.B.S.-G. and M.P. analyzed data; L.B.S.-G. and M.P.C. wrote the paper.

This work was funded by Heart and Stroke Foundation of Canada and Natural Sciences and Engineering Research Council of Canada postdoctoral fellowships (to L.B.S.-G.), a Canadian Institutes of Health Research (CIHR) short-term visit grant (to L.B.S.-G.), and CIHR Grant MOP82827 (to M.P.C.). L.B.S.-G. performed all experiments except EMG recordings performed by M.P., and cloning of lobster calcineurin A by Dr. Jibin Zhou. D.L.M. was supported by National Science Foundation Grant IBN 0077422. We give special thanks to Dr. Rosalind Silverman for sharing her expertise in cytoskeleton research and Dr. Gettemans (Ghent University), who provided the phosphoactin antibody. This paper is dedicated to the memory of Dr. Lucian Gavrila.

Correspondence should be addressed to Milton P. Charlton, Department of Physiology, Medical Sciences Building, Room 3308, University of Toronto, 1 King's College Circle, Toronto, Ontario, Canada M5S 1A8. E-mail: milton.charlton@utoronto.ca.

DOI:10.1523/JNEUROSCI.3092-12.2013

Copyright $\odot 2013$ the authors $\quad 0270-6474 / 13 / 331975-16 \$ 15.00 / 0$ requires presynaptic calcineurin activity (Silverman-Gavrila et al., 2005; Silverman-Gavrila and Charlton, 2009).

Presynaptic activation of calcineurin might be regulated by $\mathrm{Ca}^{2+}$ binding directly to calcineurin or binding to calmodulin, which in turn activates calcineurin (Stemmer and Klee, 1994). However, measurements of $\mathrm{Ca}^{2+}$ accumulation and decay in phasic terminals do not suggest that residual $\mathrm{Ca}^{2+}$ will build up at the stimulation frequency of $0.2 \mathrm{~Hz}$, which causes LFD (Msghina et al. 1999). Therefore, we sought alternative mechanisms that could cause hysteresis in activation of calcineurin. One possibility is activation of the $\mathrm{Ca}^{2+}$-dependent protease calpain, which partially cleaves the regulatory domain of calcineurin to give constitutively active phosphatase (Wang et al., 1989).

Calpains are $\mathrm{Ca}^{2+}$-dependent neutral cysteine (thiol) papainlike proteases that affect a wide variety (over 100) of endogenous cytoskeletal, membrane-associated, and regulatory proteins. Overactivation of calpain following deregulation of $\mathrm{Ca}^{2+}$ homeostasis leads to neuronal damage and death and is associated with both acute insults and chronic neurodegenerative diseases such as Alzheimer's (Liang et al., 2007), Parkinson's disease (Samantaray et al., 2008) and Huntington's disease (Majumder, 2007), epilepsy (Araújo et al., 2008), NMDA-induced excitotoxicity (Chiu et al., 2005), stroke (Shioda et al., 2006), traumatic brain injury (von Reyn et al., 2009), and spinal cord injury (Schumacher et al., 2000), making calpain an attractive drug target. Calpain also mediates sealing of severed crayfish axons (Godell et al., 1997) and has been implicated in axonal injury (Kilinc et al., 2009). 
In neurons, calpain plays a role in the regulation of synaptic processes not only during various pathological conditions, but also in physiological states. During sustained activity, activation of calpain is involved in neuronal functions such as neurotransmitter release, synaptic plasticity, vesicular transport, and structural stabilization (for review, Wu and Lynch, 2006). Calpain cleaves a variety of synaptically localized neuronal proteins such as postsynaptic density proteins, kinases, and phosphatases (for review, Wu and Lynch, 2006), neuronal $\mathrm{Ca}^{2+}$ sensor-1 (Boehmerle et al., 2007), voltage-gated sodium channel (von Reyn et al., 2009), and cyclin-dependent kinase 5 (cdk5) (Wang et al., 2007). For example, in Aplysia sensory-motor synapses, calpain plays a crucial role in synaptic facilitation and post-tetanic potentiation by being involved in refilling of depleted, releasable vesicle stores (Khoutorsky and Spira, 2005). Calpain can also cleave PKC to release PKM that is necessary for learning phenomena in Aplysia (Bougie et al., 2009; Bougie et al., 2012).

We show, using electromyography, that LFD occurs in intact animals as well as in isolated neuromuscular junction preparations. We explored the role of residual $\mathrm{Ca}^{2+}$ and calpain in LFD and propose a novel modulatory mechanism of LFD involving presynaptic activation of calcineurin by limited proteolysis by calpain.

\section{Materials and Methods}

\section{Animals and preparations}

Crayfish (Procambarus clarkii) about $6 \mathrm{~cm}$ long (Atchafalaya Biological Supply) of either sex were maintained in an aquarium at $12-13^{\circ} \mathrm{C}$ and fed lentils. The first or second walking legs were autotomized (in accordance with University Policies on the Use of Animals in Research) and pinned down to Sylgard (Dow Corning) in a Petri dish. The proximal end of the leg was inserted into a "cuff" electrode consisting of a Silastic tube containing a Pt-Ir wire connected to a stimulator, and the entire leg was covered with a physiological saline solution of (in mM) $205 \mathrm{NaCl}, 5.4 \mathrm{KCl}$, 13.5 $\mathrm{CaCl}_{2}, 2.7 \mathrm{MgCl}_{2}$, and 10 HEPES, pH 7.4 (similar to Van Harreveld, 1936). To expose the extensor muscle, the cuticle of the lateral aspect of the meropodite was cut out along with the underlying flexor muscle using a scalpel. The main leg nerve and tendons lying medial to the extensor of carpopodite muscle were carefully cut out and removed, leaving the exposed medial surface of the extensor muscle as well as the phasic and tonic axons. To minimize contractions, the extensor muscle was kept stretched.

\section{Electrophysiology}

EPSP and AP intracellular recordings to assess evoked neurotransmitter release. To determine changes in evoked neurotransmitter release, we measured the peak amplitude of the EPSPs recorded intracellularly with sharp microelectrodes $(3-15 \mathrm{M} \Omega, 3 \mathrm{M} \mathrm{KCl}$ ) from single muscle fibers of the leg extensor muscle. Transmitter release was evoked by cuff stimulation of the phasic axons. The excitation current required to excite the phasic axon is higher than that for the tonic axon, and therefore both are stimulated when the phasic axon is stimulated. However, tonic synapses usually release no quanta at the frequencies used here (Bradacs et al., 1997). Sharp microelectrodes were pulled on a Brown-Flaming micropipette puller (Sutter Instruments, model P 80/PC) and backfilled with $3 \mathrm{M}$ $\mathrm{KCl}$. Intracellular potentials detected by electrometer amplifiers (Warner Instruments, model IE-201) were low-pass filtered at $5 \mathrm{kHz}$, further amplified 10× (Warner Instruments, model LPF202), and digitized by a PowerLab/4sp data acquisition system (AD Instruments) using Scope for Windows program, version 3.6.10 (AD Instruments). Intracellular recordings of the action potential (AP) were made from secondary branches of the presynaptic phasic axon.

Data analysis. Data are presented as means and SE. Curve fitting to the time course of LFD was performed by SigmaPlot 8.0 (Systat Software) using nonlinear regression.

Spontaneous miniature EPSPs. Miniature EPSPs (mEPSPs) in the muscle fiber were detected by a low-resistance $(2-7 \mathrm{M} \Omega, 3 \mathrm{M} \mathrm{KCl})$ microelec- trode and recorded using Chart for Windows program, version 4.2 (AD Instruments). To determine whether drugs act on presynaptic or postsynaptic sites, we analyzed $\sim 130 \mathrm{mEPSPs}$ caused by spontaneous release of individual quanta before and after treatment. In crayfish neuromuscular junctions (NMJs) the mini-frequency is very low (5-10 minis per minute), and therefore we recorded for 30 min before the treatment and 60 min after treatment. The first $130 \mathrm{mEPSP}$ events well above the noise level before the treatment and the first 130 mEPSPs 30 min after the treatment were counted manually, and the amplitudes, rise to peak time, decay to $50 \%$ time, and frequencies were determined automatically using Mini Analysis Program, version 6.01 (Synaptosoft). All values are means \pm SE. Data were transferred to SigmaPlot for graphing, and SigmaStat 3.0 (SPSS) was used for statistical analysis. Student's paired $t$ tests were used to determine difference in the amplitude, rise to peak time, decay to $50 \%$ time, or frequency before and after treatments. Numbers of experiments are indicated by $n$. Probability values $(p)<0.05$ were considered to represent significant differences. The nonparametric Kolmogorov-Smirnov test (Zar, 1996) was used to detect differences in distribution of mEPSP amplitudes. Distributions were considered different using a critical probability level of $p<0.05$.

Extracellular drug application. Stock solutions were prepared in DMSO or $\mathrm{H}_{2} \mathrm{O}$ and were dissolved before use in $2 \mathrm{ml}$ saline in the static bath and mixed thoroughly to obtain final concentrations of $100 \mu \mathrm{M} N$-acethyl-Lleucyl-L-leucyl-L-norleucinal ( $N$-acetyl-Leu-Leu-Norleu-al, calpain inhibitor I, ALLN, AcLLnL-CHO) (Sigma Aldrich); $100 \mu \mathrm{M}$ 3-(4iodophenyl)-2-mercapto-(Z)-2-propenoic acid (PD 150606) inhibitor, which specifically blocks the $\mathrm{Ca}^{2+}$ binding site of calpain and noncompetitively blocks calpain activity by binding to the $\mathrm{Ca}^{2+}$-binding domain of calpain (Wang et al., 1996a); $100 \mu \mathrm{M}$ control 3-phenyl-2-mercaptopropionic acid (PD 145305) (Calbiochem); $100 \mu \mathrm{M}$ carbobenzoxyvalinyl-phenylalaninal (MDL-28170) (Enzo Life Sciences), inhibitor of calpain I and II; $50 \mu \mathrm{M}$ 1,2-bis(o-aminophenoxy)ethane- $N, N, N^{\prime}, N^{\prime}$ tetraacetic acid tetra(acetoxymethyl) ester (BAPTA-AM) (Calbiochem); and tetra(acetoxymethylester)-AM (EGTA-AM) (Invitrogen) at DMSO concentration $<0.1-0.2 \%(\mathrm{v} / \mathrm{v})$. To load cells with the $\mathrm{Ca}^{2+}$ buffer, EGTA-AM plus $1 \%$ Pluronic F-127 was applied at final concentration of $50 \mu \mathrm{M}$ in saline containing $0.2 \%$ DMSO for $30 \mathrm{~min}$, followed by an additional $30 \mathrm{~min}$ incubation to permit complete de-esterification (Zhong and Zucker, 2004). Control experiments indicate that this concentration of DMSO does not alter LFD (data not shown). Treatment with Pluronic F-127 had no effects on excitatory junction potential amplitude at $2 \mathrm{~Hz}$ (Zhong and Zucker, 2004). Drug concentrations are indicated in the text associated with each experiment and were chosen empirically based on dose-effect trials and on published concentrations used in crayfish or in other invertebrates for okadaic acid (OA), staurosporine, calcineurin autoinhibitory peptide (see references in SilvermanGavrila et al., 2005; Silverman-Gavrila and Charlton, 2009), calpain inhibitor I (Laval and Pascal, 2002), MDL-28170 (Sangenito et al., 2009), and BAPTA-AM (Zamir and Charlton, 2006).

\section{In vivo electrophysiological extracellular recordings to assess} evoked neurotransmitter release

Electromyography. Animals $(10-12 \mathrm{~cm})$ maintained as above were used within 20 days of delivery. To restrict movement and tail flipping, the extended claws, walking legs (except one of the first), and the abdomen were wrapped with Parafilm (Pechiney Plastic Packaging) after insertion of the injection needle at the dorsal thorax-abdomen junction. We recorded electromyograms (EMGs) from the extensor muscle while the motor nerve was stimulated. A similar technique was used to elicit synaptic activity in muscles of crayfish claws (Lnenicka and Atwood, 1985) and abdomen (Mercier and Atwood, 1989; Cooper et al., 1998). Recording wires of Teflon-coated copper $(0.127 \mathrm{~mm}$ diameter, $0.177 \mathrm{~mm}$ coated diameter; Medwire) were inserted through three equidistant holes drilled with a fine pin through the meropodite cuticle over the extensor muscle of the carpopodite. Stimulation wires were placed in the ischiopodite through two punctures made at the "ischio-mero" joint of the free walking leg. The recording wires in the extensor muscle were attached to an AC-coupled differential amplifier (Grass P15 D, Grass Instruments), gain of 100 , low pass filter $1 \mathrm{~Hz}$, high pass filter $1 \mathrm{kHz}$ ). Digitization 


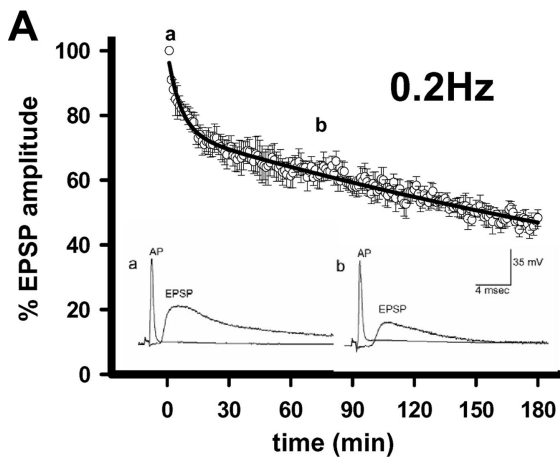

B

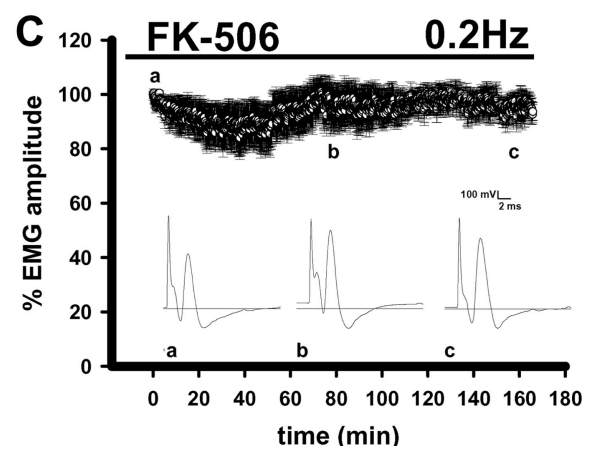

Figure 1. Low-frequency depression, LFD, occurs both in isolated neuromuscular preparations and in vivo. A, LFD at phasic synapses is a biexponential decline in transmitter release recorded at dissected leg extensor neuromuscular junction. Transmitter release declines by over $50 \%$ in $60 \mathrm{~min}$ at $0.2 \mathrm{~Hz}$ stimulation with a time constant of decay of $\tau_{1}=4 \mathrm{~min}$ and $\tau_{2}=195 \mathrm{~min}$. Inset, Simultaneous recordings of AP and EPSP during LFD at $0 \mathrm{~min}(\boldsymbol{a})$ and $75 \mathrm{~min}(\boldsymbol{b})$, showing that action potentials are not affected during LFD. $\boldsymbol{B}$, LFD at phasic synapses recorded from intact leg preparations of living animal also shows a biexponential decline in EMG amplitude. The time course of LFD elicited by stimulation at $0.2 \mathrm{~Hz}$ is similar in in vivo preparations declining to over $50 \%$ in about 25 min with time constant of decay of $\tau_{1}=2.58$ and $\tau_{2}=103.98(n=5)$. Inset examples of EEGs from intact leg preparations at times of $1.5 \mathrm{~min}(\boldsymbol{a}), 41 \mathrm{~min}(\boldsymbol{b})$, and $63 \mathrm{~min}(\boldsymbol{c})$ C, Inhibition of calcineurin with FK-506 inhibits LFD in vivo $(n=5)$. Inset, Examples of EMG extracellular potential recordings from intact leg preparations at times of $1.25 \mathrm{~min}(\boldsymbol{a}), 83 \mathrm{~min}(\boldsymbol{b})$, and 166 $\min (c)(n=5)$.

(PCI-6024E, National Instruments) of the output of the amplifier was controlled by WinWcp software (Strathclyde Electrophysiology Software, version 3.9.2.). The stimulating wires were connected to a stimulus isolation unit (model SIU5B, Grass Instruments) connected to a Grass 48 Stimulator. Stimulation started either immediately for controls or 30 min after the initial injection of drugs, a period necessary for drug circulation and equilibration. A single stimulus of $0.07 \mathrm{~ms}$ duration was delivered at $0.2 \mathrm{~Hz}$ at $1 \mathrm{~V}$ higher than the experimentally determined threshold voltage.

Data analysis. The amplitude of synaptic responses was calculated by exporting data from WinWCP to Clampfit and using the program's features to determine the voltage difference between the lowest and highest points within the evoked response of each trace. Resulting data were organized in Excel spreadsheets where mean curves were calculated and plotted. Final plots were formatted in SigmaPlot 8.0.

Drug delivery. The animals were injected with either calpain inhibitor I, MDL-28170, PD 150606, control PD 145305, BAPTA-AM, or FK-506 (Calbiochem) to give about $100 \mu \mathrm{M}$ in vivo, assuming the animals were $70 \%$ liquid by mass. Total injection volume was $150 \mu \mathrm{l}$, and stock concentrations were prepared to achieve the desired final intra-animal drug concentration. A syringe (0.5 cc U-100 insulin syringe, Becton Dickinson) was connected by several centimeters of polyethylene tubing (Becton Dickinson) to a $30 \mathrm{G}$ precision glide needle inserted into the dorsal joint between the thorax and abdomen. The tubing provided enough flexibility to allow manipulation of the syringe without disturbing the animal. Six injections of $25 \mu \mathrm{l}$ of the drug were given at 5 min intervals to allow gradual circulation throughout the crayfish and to ensure a longer lasting drug effect. In preliminary experiments animals were submerged in water, but we noticed that colored drugs appeared rapidly in the water as if they were rapidly excreted. In the experiments reported here the animals were not submerged.

\section{Immunocytochemistry}

Immunostaining. To observe calpain or calcineurin A distribution in presynaptic crayfish axon terminals, we double stained for syntaxin (used as presynaptic compartment marker) and calpain or calcineurin A. Dissected preparations of crayfish leg extensor muscles were processed for immunostaining as described previously (Silverman-Gavrila et al., 2005; Silverman-Gavrila and Charlton, 2009). Briefly, they were fixed for $1 \mathrm{~h}$ at room temperature in $4 \%$ paraformaldehyde in crayfish saline and washed for 25 min with 5 changes of saline. Nonspecific antibody binding was blocked by incubation for $1 \mathrm{~h}$ at room temperature in PBS plus $2 \%$ bovine serum albumin, $2 \%$ skim milk powder, and $0.1 \%$ Triton X-100 for permeabilization in saline. Next, specimens were incubated overnight at $4^{\circ} \mathrm{C}$ with primary antibodies: mouse monoclonal syntaxin antibody 1a-1b IgG 6D2 clone epitope from the cytoplasmic region of chicken neuronal syntaxin corresponding to amino acids 2-190 N-terminal (1:500, gift from Dr. Masami Takahashi, Kitasato University School of Medicine, Sagamihara, Japan), and rabbit polyclonal calpain antibody raised against a 28 amino acid (aa 53-80) sequence in the $\mathrm{N}$-terminal domain of Ha-CalpM deduced sequence of lobster (Homarus americanus) calpain, peptide $\left(\mathrm{NH}_{2}-\right.$ SNDYTQKRIAKGGLKIPKKGFRTLRDEC-C $\mathrm{OOH}$ ) (Yu and Mykles, 2003) diluted 1: 5000 in saline containing $0.1 \%$ Triton X-100 or rabbit polyclonal calcineurin A antibody containing a sequence corresponding to a region within amino acids 59 and 266 of calcineurin A (1:100) (Epitomics, catalog no. S2151). Following this incubation, tissues were washed 5 times for 5 min each in saline containing $0.1 \%$ Triton X-100 and then the corresponding secondary antibodies were added: Alexa Fluor 594 goat anti-rabbit IgG $(\mathrm{H}+\mathrm{L})$ or Alexa Fluor 488 goat anti-mouse IgG $(\mathrm{H}+\mathrm{L})$ highly cross-adsorbed (Invitrogen), diluted 1: 1000 in saline plus $0.1 \%$ Triton $\mathrm{X}-100$ for $1 \mathrm{~h}$ at $4^{\circ} \mathrm{C}$ followed by 5 washes at 5 min interval in saline plus $0.1 \%$ Triton X-100 to remove the secondary antibodies. Control preparations in which only the secondary antibodies were applied without the primary antibodies showed no staining with secondary antibodies (data not shown). Thin slices of the muscle surface cut with a razor blade scalpel were mounted on slides in SlowFade antifade kit (Invitrogen) and imaged with Leica DNLFS confocal laser scanning microscope running a TCS LS software (Leica Microsystems) using $488 \mathrm{~nm}$ and $594 \mathrm{~nm}$ excitation lines and either a $63 \times$ numerical aperture (NA) 1.32 or $40 \times$ NA 1.25 objective lens. Images from different focal planes were stacked as layers and combined in projected images. We examined five preparations stained for calpain and syntaxin and five preparations stained for calcineurin A and syntaxin.

We also double stained for tubulin (monoclonal anti- $\alpha$-tubulin antibody clone DM1A, purified mouse immunoglobulin (Sigma, catalog no. $\mathrm{T}$ 6199) diluted 1:100) and actin (rabbit polyclonal anti-actin (Abcam, 1:100, catalog no. ab 1801) preparation after LFD inhibition by calpain inhibitor I. As controls we used unstimulated preparations, preparations treated with calpain inhibitor I, and preparations after LFD. In addition, we double stained for phosphoactin (1:100, raised in rabbit against a highly conserved actin phospho-peptide CGYSFTTTpAEREIVR (T'jampens et al., 1999) encompassing Thr of Physarum actin (Vandekerckhove and Weber, 1978) after LFD inhibition by calpain inhibitor I. As controls we used unstimulated preparations and preparations after LFD. We examined three to four preparations for each experimental set, and the pattern predominant in at least $80 \%$ of the analyzed preparations was presented as an exemplar. We used the program ImageJ (http://rsb.info.nih.gov/ij/) to 
measure the mean intensity of the boutons using the free-hand selection tool and subtracting the background intensity.

Western blotting. Antibodies were tested for specificity by Western blot analysis of proteins extracted from crayfish ventral nerve cords and presynaptic axonal processes. The presynaptic axonal processes are phasic and tonic axons and boutons extracted from preparations by detaching them from the extensor muscle with fine pins after treatment with collagenases (Silverman-Gavrila and Charlton, 2009). Protein extracts were obtained by freezing the sample in liquid nitrogen and homogenization in a protein lysis buffer containing $50 \mathrm{~mm}$ Tris-HCl, $\mathrm{pH}$ 6.8, $100 \mathrm{~mm}$ dithiothreitol, $2 \%$ SDS (sodium dodecyl sulfate), and 10\% glycerol. This process was repeated twice, followed by boiling for $10 \mathrm{~min}$, centrifugation at $12,000-18,000 \times g$ for $10 \mathrm{~min}$, and collection of the supernatant. Protein extracts were separated by SDS-PAGE (SDS-polyacrylamide gel electrophoresis) on a ready-made $10-15 \%$ gel (Bio-Rad Laboratories) and transferred to nitrocellulose membrane using a Mini-PROTEAN III electrophoresis Unit and Mini Trans-Blot system (Bio-Rad Laboratories). As molecular weight markers we used prestained protein ladder (ThermoFisher, Fermentas) or (Bio-Rad). The membrane was blocked overnight in $5 \%$ skim milk plus $0.05 \%$ Tween 20 blocking solution and then probed with primary Ha-CalpM antibody (1:5000), followed by washing in PBS and labeling with ECL goat anti-rabbit IgG secondary antibody conjugated to horseradish peroxidase (1:2000-5000) (GE Healthcare). The immuno-decorated protein signals were detected by enhanced chemiluminescence using an ECL reagent kit (GE Healthcare), light-sensitive imaging film (Clonex) and Konica film processor SRX-101A.

Western blotting for phosphoactin. Protein extracts from presynaptic processes were obtained from unstimulated preparations, preparations stimulated at $0.2 \mathrm{~Hz}$ to cause LFD, and preparations stimulated at $0.2 \mathrm{~Hz}$ and treated with calpain inhibitor I and were separated by SDS-PAGE as described previously (Silverman-Gavrila and Charlton, 2009). The membrane was probed with primary phosphoactin antibody (1:100) and, after stripping, with rabbit polyclonal anti-actin (Abcam, 1:100) and imaged as described (see above, Western blotting). We used the integrated density function of ImageJ to measure the area and mean gray value intensity of the bands.

Western blotting for calcineurin cleavage by calpain. Crayfish ventral nerve cord ganglia were dissected from animals on ice, washed in ice-cold $0\left[\mathrm{Ca}^{2+}\right]$ saline, and frozen in liquid nitrogen. Frozen tissue was homogenized on ice with a motorized pestle in an ice-cold protein lysis buffer containing $50 \mathrm{~mm}$ Tris- $\mathrm{HCl}, \mathrm{pH}$ 7.4. The homogenate was aliquoted to three vials on ice and treated with ice-cold solutions of either $90 \mathrm{~mm}$ $\mathrm{NaCl}, 540 \mathrm{~mm}$ HEPES, $10 \mathrm{~mm} \mathrm{CaCl}_{2}$, pH 7.4, or $90 \mathrm{~mm} \mathrm{NaCl}, 540$ mм HEPES, $10 \mathrm{~mm} \mathrm{CaCl}_{2}$, pH 7.4 plus calpain inhibitor I or $0 \mathrm{Ca}^{2+}(135$ mM EGTA, $540 \mathrm{~mm}$ HEPES $\mathrm{pH}$ 7.4). Since there is a maximum of $13.5 \mathrm{mM} \mathrm{Ca}^{2+}$ in the ganglion, we added $0.1 \mathrm{vol}$ of $135 \mathrm{~mm}$ EGTA to chelate almost all $\mathrm{Ca}^{2+}$. Protein extracts were loaded on gels after $15 \mathrm{~min}$ at room temperature for inhibitor treatment and $0 \mathrm{Ca}^{2+}$ and for 5,10 , or $15 \mathrm{~min}$ in the presence of $10 \mathrm{mM} \mathrm{CaCl}_{2}$ and then separated by SDS-PAGE on ready-made 7.5\% Mini-Protean TGX precast gels (Bio-Rad Laboratories) on ice and transferred to nitrocellulose membrane (Millipore) using a Mini-Protean III electrophoresis Unit and Mini-trans-Blot system (Bio-Rad Laboratories) at constant voltage of $25 \mathrm{~V}$ at $4^{\circ} \mathrm{C}$ for $2-2.5 \mathrm{~h}$ in transfer buffer (25 mm Tris base, $192 \mathrm{~mm}$ glycine, 20\% methanol). To estimate the molecular weight we used Bio-Rad broad range molecular weight markers (Bio-Rad). The membrane was incubated $1 \mathrm{~h}$ at room temperature in blocking solution (5\% bovine serum albumin in PBS) and then probed with mouse anti-tubulin antibody (Sigma) for loading control normalization of the signal to an internal protein standard (1:500 diluted in PBS-T (PBS plus $0.1 \%$ Tween 20). The membrane was washed in PBS-T twice quickly, then twice for 5 min each in PBS-T, followed by labeling with ECL goat anti-mouse IgG secondary antibody conjugated to horseradish peroxidase (1:2000-5000) (GE Healthcare) for $2 \mathrm{~h}$. The immuno-decorated protein signals were detected by enhanced chemiluminescence using an ECL reagent kit (GE Healthcare), light-sensitive imaging film (Clonex) and Konica film processor SRX-101A. The membrane was then stripped and probed overnight at $4^{\circ} \mathrm{C}$ with primary antibody rabbit polyclonal anti-calcineurin A alpha isoform (1:500). The
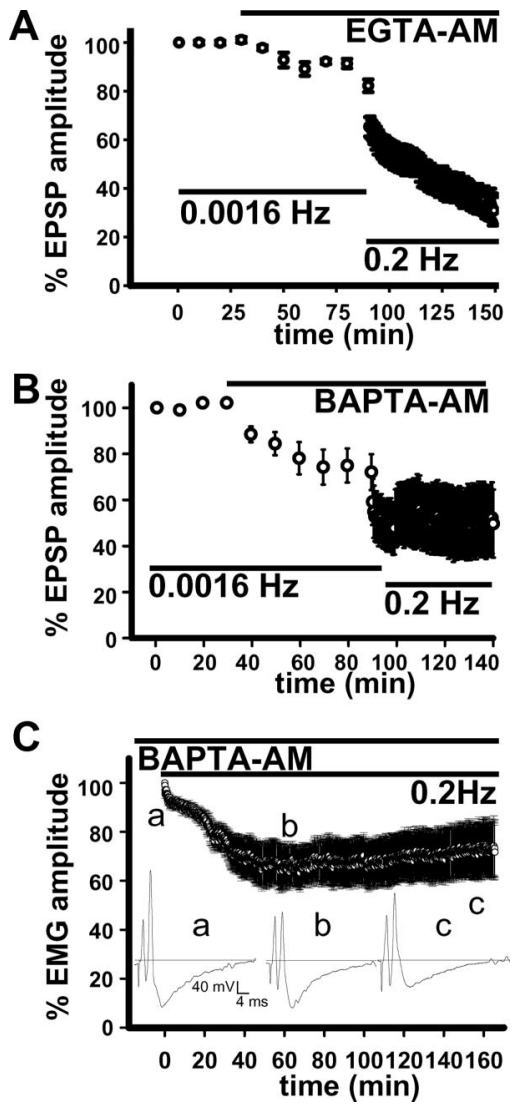

Figure 2. Slow and fast $\mathrm{Ca}^{2+}$ chelators have different effects on LFD; slow intracellular $\mathrm{Ca}^{2+}$ buffering does not inhibit LFD, however LFD is affected by fast $\mathrm{Ca}^{2+}$ chelators. A, Application of the slow $\mathrm{Ca}^{2+}$ chelator EGTA-AM did not abolish LFD. After 30 min of control recordings at $0.0016 \mathrm{~Hz}$ (nondepressing stimulation frequency), EGTA-AM was added to the bath for $60 \mathrm{~min}$ and then the frequency of stimulation was increased to $0.2 \mathrm{~Hz}$. Since EGTA-AM caused a small decrease in transmitter release at $0.0016 \mathrm{~Hz}$, it is likely that a physiologically relevant intracellular concentration of EGTA had been obtained; however, it had minimal effects on LFD $(n=5)$. B. Application of BAPTA-AM inhibited LFD $(n=5)$. After 30 min of control recordings at $0.0016 \mathrm{~Hz}$, BAPTA-AM was added to the bath for $60 \mathrm{~min}$ and then the frequency of stimulation was increased to $0.2 \mathrm{~Hz}$. Measurements of EPSP amplitude are normalized to the first EPSP. Each point is the average of six consecutive EPSPs in five to seven experiments \pm SE. C. BAPTA-AM also inhibited LFD in vivo $(n=5)$. Inset, Examples of EMG recordings from intact leg preparations at $2.5 \mathrm{~min}(\boldsymbol{a}), 65 \mathrm{~min}(\boldsymbol{b})$, and $168 \mathrm{~min}(\boldsymbol{c})$.

membrane was washed in PBS-T twice quickly, then twice for 5 min each in PBS-T followed by labeling with ECL goat anti-rabbit IgG secondary antibody conjugated to horseradish peroxidase (1:2000-5000) (GE Healthcare) for $2 \mathrm{~h}$ and imaged similarly as tubulin antibody.

Fluorimetric detection of calpain enzymatic activity in vitro. The assay is based on a calpain cleavable substrate peptide labeled with a fluorescence resonance energy transfer (FRET) donor-acceptor pair, 5-carboxyfluorescein (5-FAM), and a quencher, QXL 520 (AnaSpec), shown to be cleaved by human calpain 1 purified from erythrocytes and rat calpain 2 recombinant (Zhu et al., 2009; Novgorodov et al., 2011). Fluorescence of 5-FAM is quenched by QXL 520 until the peptide is cleaved by calpain. Upon cleavage, fluorescence of 5-FAM is recovered and can be continuously monitored. Increase in 5-FAM fluorescence is proportional to calpain activity. The assay can detect both calpain 1 and 2 activities. The assay $(n=4)$ was performed in a 24 well plate by mixing protein extracts from ganglia with the substrate $(20 \mu \mathrm{M}$ working solution, stock dissolved in DMSO) and fluorescence imaged with an Ettan DIGE Imager (GE Healthcare) at $\lambda_{\mathrm{ex}}=480 \mathrm{~nm} / \lambda_{\mathrm{em}} 530 \mathrm{~nm}$ in various experimental conditions.

Cloning and expression of lobster Homarus americanus calcineurin A. A cDNA encoding a partial calcineurin A sequence was obtained with RTPCR using degenerate primers to a highly conserved sequence in homol- 

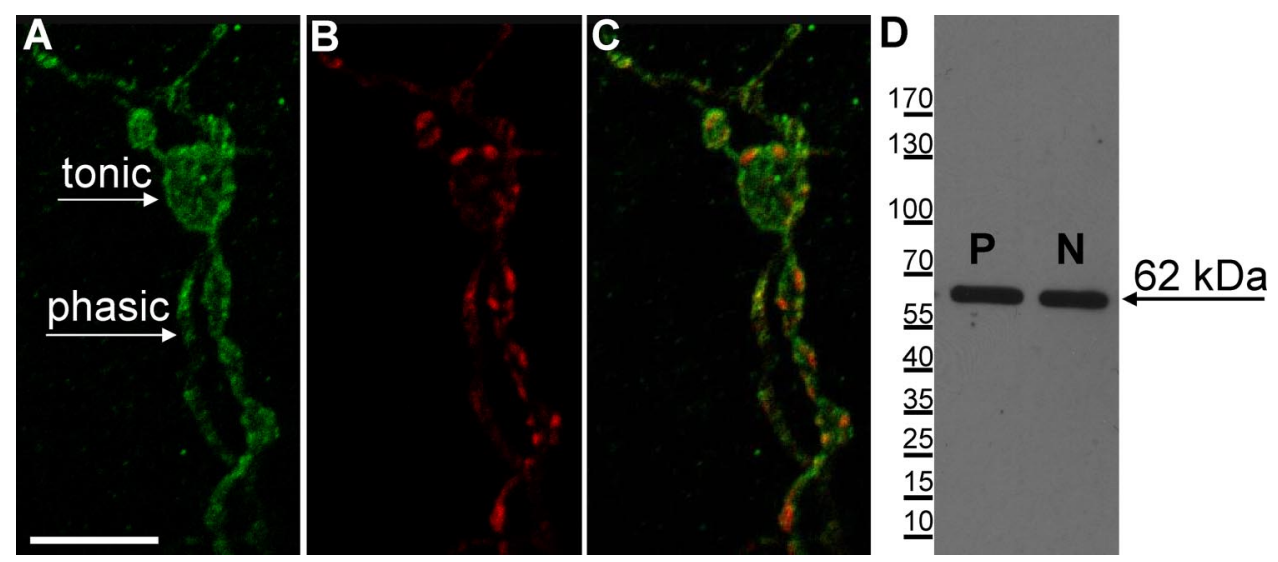

Figure 3. Calpain is present at crayfish phasic and tonic terminals. Double immunostaining confocal images showing the presence of calpain (B, red) at both phasic and tonic boutons and its distribution relative to the presynaptic membrane marker syntaxin $(\boldsymbol{A}$, green). $\boldsymbol{C}$, Overlay image of $\boldsymbol{A}$ and $\boldsymbol{B}$, colocalization (yellow). $\boldsymbol{D}$, Western blot analysis for calpain. Anti-calpain antibody recognized a single band of an $\sim 62 \mathrm{kDa}$ protein in both crayfish nerve cord $(\mathrm{N})$ and presynaptic structures $(\mathrm{P})$. The Western blot demonstrates that the antibody has appropriate specificity. Arrow indicates the $62 \mathrm{kDa}$ position relative to the molecular mass standards represented by black lines.
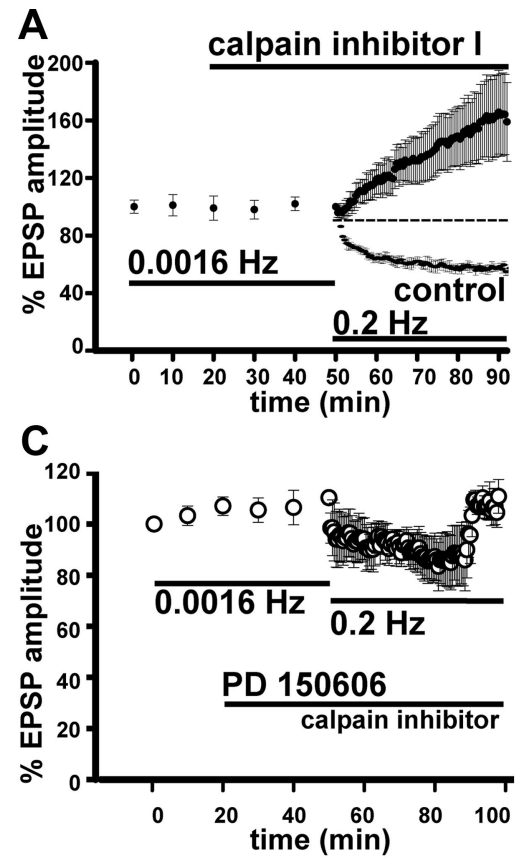

B
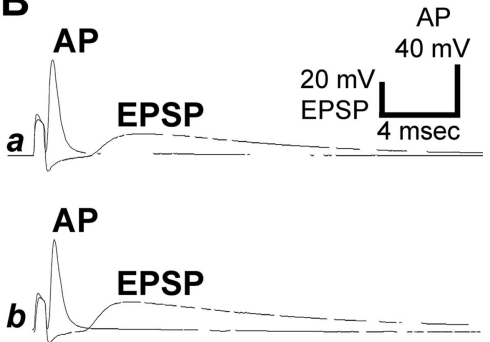

D

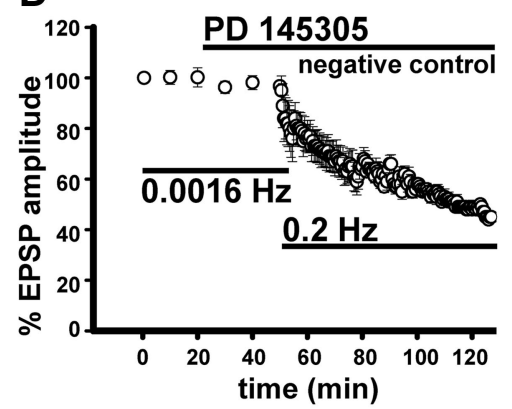

E

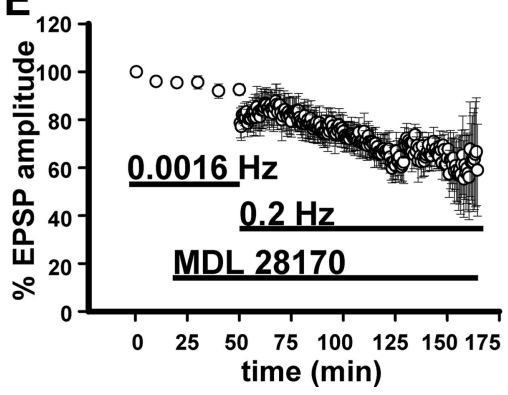

Figure 4. Calpain inhibitors inhibit LFD. $A$, Calpain inhibitor I (100 $\mu \mathrm{M})$ applied at NMJs 30 min prior to starting stimulation at $0.2 \mathrm{~Hz}$ inhibits depression. Without the calpain inhibitor there would be profound depression after $30 \mathrm{~min}$ of stimulation. $\boldsymbol{B}$, Representative simultaneous recordings of presynaptic APs from axons and EPSPs from muscle fiber at $0 \mathrm{~min}(\boldsymbol{a})$ and $15 \mathrm{~min}(\boldsymbol{b})$ of stimulation at $0.2 \mathrm{~Hz}$ show an increase in the EPSP amplitude with no effect on the action potential. C, PD150606, another calpain inhibitor applied $30 \mathrm{~min}$ before stimulation, also inhibited LFD. D, Control compound PD145305 did not inhibit LFD. E, Another calpain inhibitor, MDL 28170, also inhibited LFD. After recording transmitter release for 20 min at $0.0016 \mathrm{~Hz}$ (stimulation when neurotransmitter release was stable), the drugs were added and transmitter release was recorded for an additional $30 \mathrm{~min}$, and then the frequency of stimulation was increased to $0.2 \mathrm{~Hz}$ to invoke LFD. Measurements of EPSP amplitude were normalized to the first EPSP. Each point is the average of six consecutive EPSPs in five experiments \pm SE for each treatment. ogous genes from other species. Sequencing showed that it encodes the catalytic domain of calcineurin. We thank Dr. Jibin Zhou at Colorado State University (Fort Collins, CO) for providing the nucleotide sequence.

\section{Results}

\section{LFD in vivo}

In the extensor muscle of excised legs, transmitter release at phasic synapses measured as EPSPs with intracellular microelectrodes declines biexponentially $\left(\tau_{1}=4 \mathrm{~min}\right.$ and $\tau_{2}$ $=195 \mathrm{~min} ; n=5$ ) by over $50 \%$ in $60 \mathrm{~min}$ with stimulation at $0.2 \mathrm{~Hz}$ (Fig. 1A) (Silverman-Gavrila et al., 2005; SilvermanGavrila and Charlton, 2009). We wondered whether the depression is an experimental artifact caused by the lack of hemolymph circulation or by an insufficiency in the composition of saline used to bathe the preparation. To examine this possibility, we recorded EMGs from extensor muscles in intact animals while the motor nerve was stimulated via implanted wires. When stimulation was applied at $0.2 \mathrm{~Hz}$ the synaptic response declined similarly as the LFD that occurred in excised NMJ preparations, suggesting that LFD is a physiological process $(n=5)$ (Fig. 1B).

\section{LFD in vivo requires}

calcineurin activity

Previously we showed that LFD at phasic synapses in excised legs involves presynaptic activation of calcineurin and is blocked by the inhibitor FK-506 (Silverman-Gavrila and Charlton, 2009). Similarly, when FK506 was injected into the intact animal, LFD was inhibited $(n=5)$ (Fig. $1 C)$. This result shows that both the time course and drug sensitivity of LFD recorded in vivo and in excised legs are similar, and therefore both measurements likely represent the same phenomenon (Fig. 1C). 
$\mathrm{Ca}^{2+}$ sensor for activation of calcineurin is close to the $\mathrm{Ca}^{2+}$ source

Since LFD occurs with stimuli at $5 \mathrm{~s}$ intervals, it seems that calcineurin activity following single action potentials must be sustained between stimuli, or rephosphorylation by kinases must be relatively slow. However, since LFD can be reversed by application of calcineurin blockers (Silverman-Gavrila and Charlton, 2009), kinase activity is sufficient to restore phosphorylation with stimulation at $5 \mathrm{~s}$ intervals. Sustained activity of calcineurin could occur if the $\mathrm{Ca}^{2+}$ signal is prolonged but the time course of the $\mathrm{Ca}^{2+}$ signal is relatively brief. $\mathrm{Ca}^{2+}$ signals from single action potentials in the phasic terminals have not been resolved, but measurements made in the larger inhibitory and excitatory terminals on the crayfish opener muscle (Vyshedskiy and Lin, 2000; DeMill and Delaney, 2005) show that $\mathrm{Ca}^{2+}$ from single action potentials decays within $200 \mathrm{~ms}$. Moreover, $\mathrm{Ca}^{2+}$ accumulation in phasic terminals with $1 \mathrm{~Hz}$ stimulation is barely detectable (Msghina et al., 1999), and based on a nearly linear relationship between frequency of stimulation and both increase and decay in $\mathrm{Ca}^{2+}\left(\Delta \mathrm{Ca}^{2+}\right)$ at low frequency stimulation (Msghina et al., 1999) we estimated that the $5 \mathrm{~nm}$ increase in $\left[\mathrm{Ca}^{2+}\right]$ will decay with a time constant $\sim 0.0782 \mathrm{~s}$ at $0.2 \mathrm{~Hz}$ stimulation. Thus, it is unlikely that calcineurin is continually activated by presynaptic residual $\mathrm{Ca}^{2+}$ accumulation at the frequency we used. To test this hypothesis we added the slow $\mathrm{Ca}^{2+}$ chelator, EGTA-AM, and observed its effect on LFD. After $30 \mathrm{~min}$ of control recordings in NMJ preparations at $0.0016 \mathrm{~Hz}$ (nondepressing stimulation frequency), EGTA-AM was added to the bath for $60 \mathrm{~min}$ and then the frequency of stimulation was increased to $0.2 \mathrm{~Hz}$. Since EGTA-AM caused a small decrease in transmitter release at $0.0016 \mathrm{~Hz}$, it is likely that a physiologically relevant intracellular concentration of EGTA had been obtained (Hochner et al., 1991; Winslow et al., 1994; Borst and Sakmann, 1999); however, application of EGTA-AM $(50 \mu \mathrm{M})$ failed to completely prevent LFD $(n=5)$ (Fig. 2A).

We next examined the effect of the fast $\mathrm{Ca}^{2+}$ chelator, BAPTA-AM. After $30 \mathrm{~min}$ of control recordings at $0.0016 \mathrm{~Hz}$, BAPTA-AM was added to the bath for $60 \mathrm{~min}$ and then the frequency of stimulation was increased to $0.2 \mathrm{~Hz}$. Application of BAPTA-AM inhibited LFD (Fig. 2B). A similar effect of BAPTA-AM was observed in intact animals (Fig. 2C). These data indicate that buffering of bulk cytoplasmic residual $\mathrm{Ca}^{2+}$ does not affect the induction of LFD and that the $\mathrm{Ca}^{2+}$ sensor for LFD may be close to the plasma membrane $\mathrm{Ca}^{2+}$ channels, where a large $\mathrm{Ca}^{2+}$ signal is available (Adler et al., 1991). One possible $\mathrm{Ca}^{2+}$ sensor involved in LFD is the $\mathrm{Ca}^{2+}$-sensitive protease calpain. Calpain could produce hysteresis of calcineurin activity by cleaving the regulatory domain of calcineurin to produce constitutively active enzyme (Manalan and Klee, 1983; Wang et al., 1989; Wu et al., 2004).

\section{Calpain is present at the nerve terminals}

To determine whether calpain is present at the presynaptic terminals of crayfish, we immunostained for calpain and syntaxin (a presynaptic compartment marker). Calpain immunoreactivity was evident at both phasic and tonic terminals (Fig. 3A-C). Western blot analysis showed that anti-calpain antibody recognized a single protein band of $\sim 62 \mathrm{kDa}$ in both crayfish nerve cord $(\mathrm{N})$ and presynaptic processes (P) (Fig. 3D), which was similar to the $62 \mathrm{kDa}$ isoform from lobster muscle reported by $\mathrm{Yu}$ and Mykles (2003).
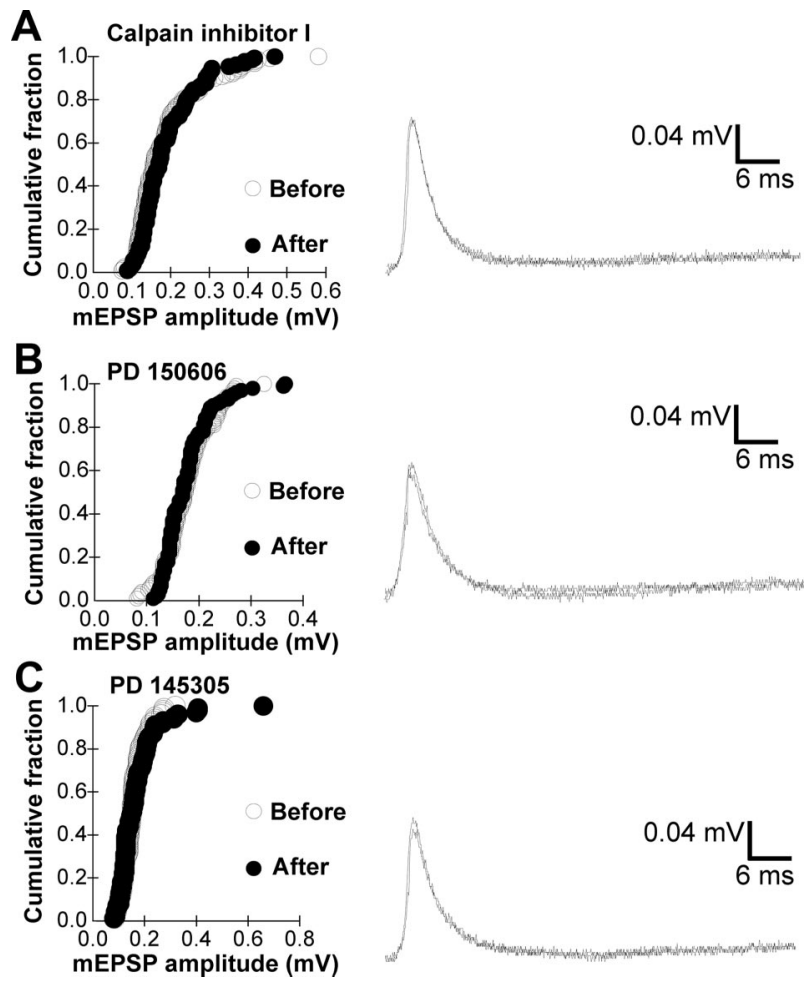

Figure 5. Calpain inhibitors have no obvious postsynaptic effects. $A$, Cumulative amplitude distribution of mEPSPs was not affected by $100 \mu \mathrm{m}$ calpain inhibitor I (Kolmogorov-Smirnov test, $p=0.33$ for the example experiment; $n=5$ ). Inset, Averages of $130 \mathrm{mEPSP}$ s recorded before and after treatment with $100 \mu \mathrm{m}$ calpain inhibitor I show little effect on rise to peak time $(1.22 \pm 0.05$ ms versus $1.31 \pm 0.05 \mathrm{~ms})$ and decay to $50 \%$ time $(1.21 \pm 0.07$ ms versus $1.42 \pm$ $0.07 \mathrm{~ms}$ ) for this example experiment. $\boldsymbol{B}$, Cumulative amplitude distribution of mEPSPs was not affected by PD 1506606 (Kolmogorov-Smirnov test, $p=0.79$ for the example experiment; $n=5$ ). Inset, Averages of $100 \mathrm{mEPSPs}$ recorded before and after treatment with calpain inhibitor PD 150606 show little effect on rise to peak time ( $1.61 \pm 0.06 \mathrm{~ms}$ versus $1.62 \pm 0.06 \mathrm{~ms})$ and decay to $50 \%$ time $(1.52 \pm 0.16 \mathrm{~ms}$ versus $1.71 \pm 0.17 \mathrm{~ms})$ for this example experiment. C, Application of control compound PD 145305 did not affect mEPSPs amplitude distribution (Kolmogorov-Smirnov test, $p=0.44$ for the example experiment; $n=5$ ). Inset, Averages of $100 \mathrm{mEPSPs}$ recorded before and after treatment with PD 145305 show little effect on rise to peak time ( $1.34 \pm 0.05 \mathrm{~ms}$ versus $1.30 \pm 0.05 \mathrm{~ms})$ and decay to $50 \%$ time $(1.32 \pm 0.13 \mathrm{~ms}$ versus $1.36 \pm 0.07 \mathrm{~ms}$ ) for this example experiment.

\section{Calpain inhibitors inhibit LFD in NMJ preparations}

To determine whether calpain inhibition affects LFD, we applied calpain inhibitors and monitored their effects on LFD. Preparations were first stimulated at $0.0016 \mathrm{~Hz}$ to produce a stable baseline, drugs were then applied, and later stimulation frequency was increased to $0.2 \mathrm{~Hz}$. Calpain inhibitor I (100 $\mu \mathrm{M})$, MDL-28170 $(100 \mu \mathrm{M})$, and PD $150606(100 \mu \mathrm{M})$, but not the control PD 145305(100 $\mu \mathrm{M})$, inhibited LFD (Fig. 4A-E). Control experiments to investigate possible activity-independent effects of these drugs were performed with stimulation at $0.0016 \mathrm{~Hz}$ when neurotransmitter release was stable to allow assay of transmitter release without significant depression. The drugs had minimal effect when stimulation frequency was $0.0016 \mathrm{~Hz}$. Nonstimulusdependent effects were not crucial factors in preventing or enhancing the appearance of depression, because there were no effects on basal transmission (Fig. $4 A-E$ ). Calpain inhibitor I had an effect similar to that of calcineurin inhibitors (SilvermanGavrila et al., 2005) that also reversed the LFD and caused facilitation, suggesting that the substrates they inhibit act in a common pathway. Although the degree of inhibition was different with the other two inhibitors used, MDL 28170 and PD150606, all calpain 
Table 1. Summary of mEPSP analysis before and after treatment with various calpain inhibitors

\begin{tabular}{|c|c|c|c|c|c|c|}
\hline \multirow[b]{3}{*}{ Parameter } & \multicolumn{6}{|c|}{ Treatment $(n=5)$} \\
\hline & \multicolumn{2}{|c|}{ Calpain inhibitor I } & \multicolumn{2}{|l|}{ PD 150606} & \multicolumn{2}{|l|}{ PD145305 } \\
\hline & Before & After & Before & After & Before & After \\
\hline Amplitude (mV) & $0.16 \pm 0.01$ & $0.17 \pm 0.01$ & $0.19 \pm 0.02$ & $0.18 \pm 0.02$ & $0.15 \pm 0.03$ & $0.15 \pm 0.01$ \\
\hline Frequency (Hz) & $0.06 \pm 0.01$ & $0.07 \pm 0.01$ & $0.10 \pm 0.02$ & $0.14 \pm 0.04$ & $0.08 \pm 0.02$ & $0.07 \pm 0.02$ \\
\hline Rise to peak time (ms) & $1.4 \pm 0.06$ & $1.43 \pm 0.07$ & $1.53 \pm 0.14$ & $1.39 \pm 0.18$ & $1.32 \pm 0.08$ & $1.29 \pm 0.08$ \\
\hline Decay to $50 \%$ time (ms) & $1.23 \pm 0.1$ & $1.4 \pm 0.1$ & $1.63 \pm 0.25$ & $1.53 \pm 0.2$ & $1.16 \pm 0.14$ & $1.14 \pm 0.1$ \\
\hline
\end{tabular}

The amplitude, frequency, rise time, and decay time were measured for mEPSPs released before $(n \sim 130)$ and 30 min after drug treatment $(n \sim 130)$ for each of the five experiments for each experimental condition. None of the fou parameters were affected by these drugs $(p>0.05, n=5)$.
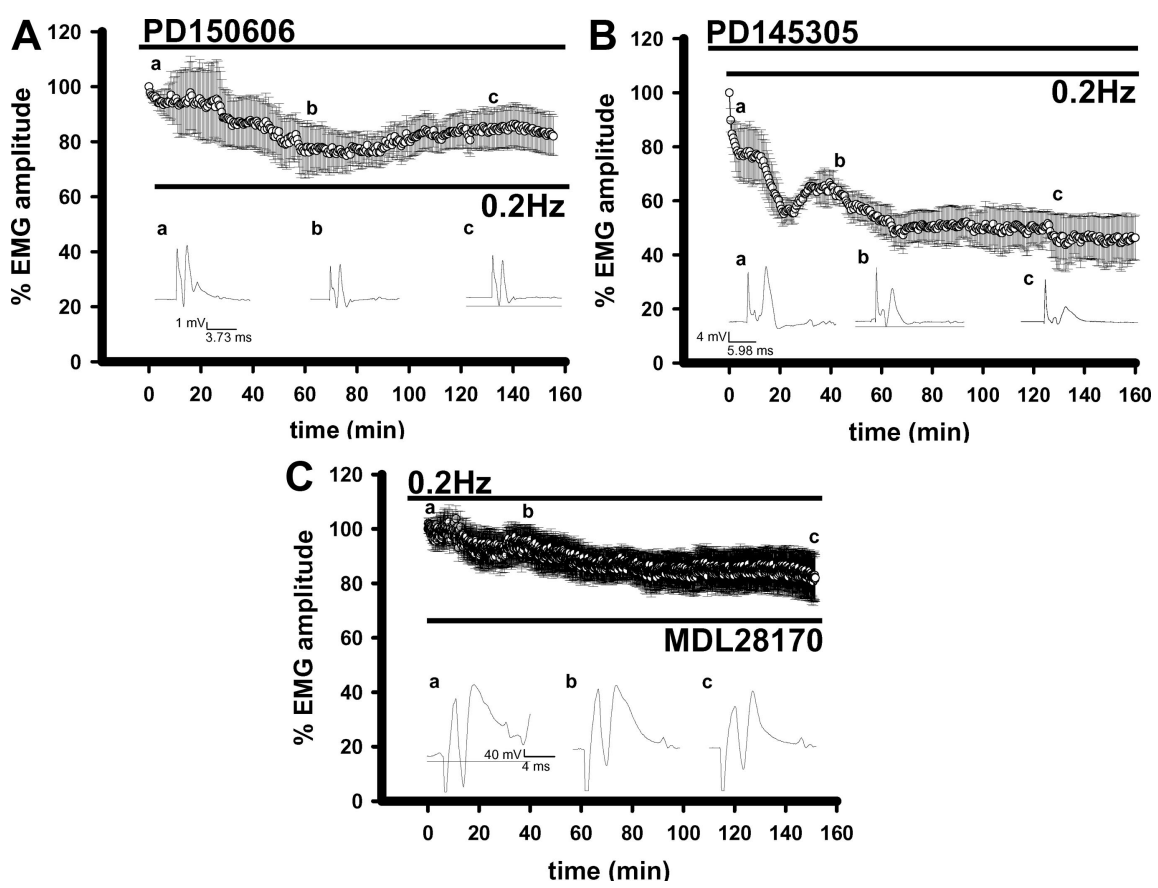

Figure 6. Calpain inhibition abolishes LFD caused by stimulation at $0.2 \mathrm{~Hz}$ in intact animals. $\boldsymbol{A}$, Calpain inhibitor PD 150606 limits LFD to 80\%. Inset, Examples of EMG from intact leg preparations at times of 0.5 (a), $63 \mathrm{~min}(\boldsymbol{b})$, and $134 \mathrm{~min}$ (c). $\boldsymbol{B}$, Control compound PD 145305 did not inhibit LFD. Inset, Examples of EMG from intact animal at times of $0.5 \mathrm{~min}(\boldsymbol{a}), 40 \mathrm{~min}(\boldsymbol{b})$, and 140 $\min (\boldsymbol{c})$. C, Another calpain inhibitor, MDL 28170, also inhibited LFD. Inset, Examples of EMGs at times of $2 \mathrm{~min}(\boldsymbol{a}), 40 \mathrm{~min}(\boldsymbol{b})$, and $160(c) ; n=5$ for all treatments. After the inhibitor was injected in seven successive injections separated by 5 min during a 30 min period, the preparation was stimulated at $0.2 \mathrm{~Hz}$.

inhibitors we used do inhibit LFD. Differences in the degree of inhibition of calpain activity reported here and by others such as To et al., (2008) might be explained by differences in potency or specificity for a particular species - an important issue, especially for invertebrates. Similar effects produced by a variety of calpain inhibitors with different mechanisms of action indicate that calpain activity is the most likely mechanism through which each of these compounds affect LFD. Calpain inhibitor I, like MDL 28170, is a cell-permeable peptidomimetic inhibitor that targets the enzymatic site, whereas PD150606 is a cell-permeable $\alpha$-mercaptoacrylate nonpeptide, noncompetitive calpain inhibitor directed toward the calcium binding sites of calpain (Lin et al., 1997). Calpain inhibitor I acts as a competitive inhibitor of neutral cysteine proteases, but at high concentrations it also inhibits the proteasome. In contrast, MDL 28170 is a specific inhibitor for calpain I and II, and PD150606 selectively inhibits calpains relative to other proteases, such as cathepsin B and cathepsin L. PD150606 targets the calpain calcium-binding domain not found in cathepsins and, therefore, is highly specific ( $>600$-fold) for calpains in comparison with cathepsins (Wang et al., 1996a). We performed experiments with proteasome inhibitors such as lactacystin, but no effect was observed on LFD both in free living organisms and in dissected preparations (our unpublished data). Because calpain inhibitor I, PD150606, and MDL 28170 all yielded inhibitory effects on LFD, we conclude that inhibition of calpain rather than other cross-inhibited proteases is responsible for the effects seen on synaptic transmission.

To examine presynaptic and postsynaptic effects of these drugs we recorded mEPSPs, which are the responses to spontaneously released single quanta of transmitter. We measured the amplitude and frequency for mEPSPs released before and $30 \mathrm{~min}$ after drug treatment for each of the five experiments (Fig. 5) and each experimental condition, and the results are summarized in Table 1.

Calpain inhibitor I $(100 \mu \mathrm{M})$ did not affect the average mEPSP amplitude ( $p=$ 0.10 ) or the amplitude distribution (Kolmogorov-Smirnov test, $p=0.33$ for the example experiment) (Fig. 5A). The frequency $(p=0.09)$, rise to peak time $(p=$ $0.3)$, and decay to $50 \%$ time $(p=0.21)$ of mEPSPs did not change with calpain inhibitor I (Fig. 5A, inset). PD 150606 did not affect the amplitude of spontaneous mEPSPs $(p=0.88)$ (Fig. $5 B)$. The Kolmogorov-Smirnov test $(p=0.79)$ did not detect statistically significant changes between the amplitude distributions of mEPSPs before and after treatment with PD 150606 (Fig. 5B). Averages of 130 mEPSPS recorded before and after the treatment show that the mEPSP rise to peak time $(p=1.18)$, and the decay to $50 \%$ time $(p=$ 0.43 ) did not change (Fig. $5 B$, inset). The frequency of spontaneous mEPSPs was also not significantly affected following application of PD150606 ( $p=0.07)$. The control compound PD145305 treatment did not have statistically significant effects on the mEPSPs amplitude ( $p=0.78$ ), amplitude distributions (Kolmogorov-Smirnov test for example experiment, $p=0.44$ ) (Fig. $5 C$ ), rise to peak time ( $p=$ $0.74)$, the decay to $50 \%$ time $(p=0.89)$ (Fig. $5 C$, inset), and frequency $(p=0.71)$. Mini-EPSPS analysis showed that these drugs did not affect the amplitude, amplitude distributions, frequency, rise time, and decay time of mEPSPs, suggesting that they act presynaptically and do not have postsynaptic effects. Therefore, it is unlikely that these drugs affect postsynaptic receptors or kinetics of individual release events. 

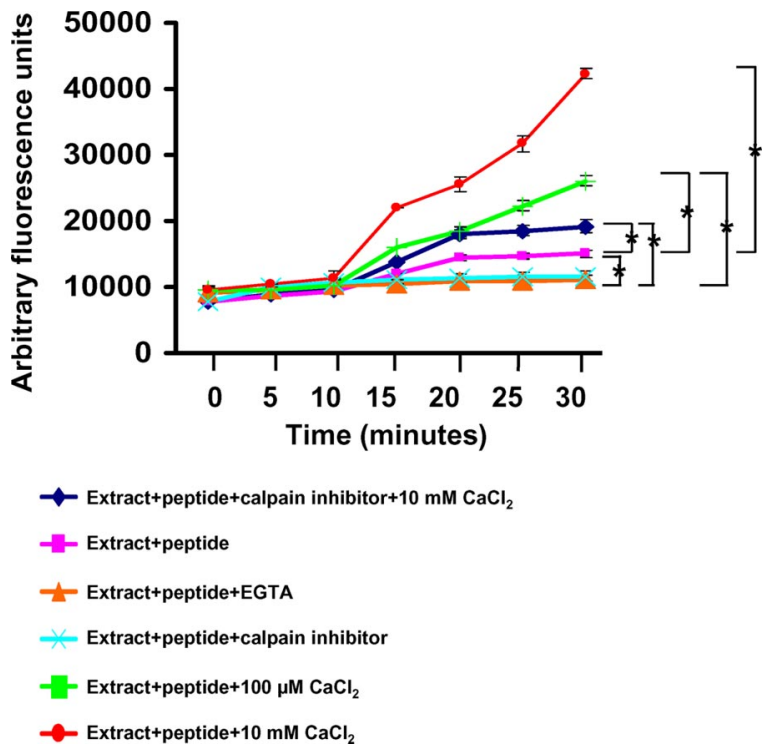

Figure 7. Calpain activity is modulated by $\mathrm{Ca}^{2+}$ and calpain inhibitors. Fluorescence caused by cleavage of 5-FAM/QXL 520 FRET — calpain substrate peptide was measured in four replicate CNS protein lysates after 30 min incubation under various conditions: extract + peptide substrate + EGTA; extract + peptide substrate + calpain inhibitor l; extract + peptide substrate; extract + peptide substrate $+100 \mu \mathrm{m} \mathrm{CaCl}$; extract + peptide substrate + calpain inhibitor I $+10 \mathrm{~mm} \mathrm{CaCl}$; extract + peptide substrate $+10 \mathrm{~mm} \mathrm{CaCl}$. Addition of $100 \mu \mathrm{m}$ $\mathrm{CaCl}_{2}$ increased the activity of enzyme compared with the control (peptide + extract) that had only the endogenous $\mathrm{C}^{2+}$ released from breaking the cells $(p=0.022)$, and the control where $\mathrm{Ca}^{2+}$ was removed by chelation with EGTA ( $\left.p=0.002\right)$. Incubation in the presence of calpain inhibitor I reduced calpain activity in a condition where no additional $\mathrm{Ca}^{2+}$ was present $(p=$ $0.002)$ and also when additional $\mathrm{Ca}^{2+}(10 \mathrm{~mm})$ was added $(p=0.003)$. Inhibition of calpain with inhibitors was partially rescued by addition of $10 \mathrm{~mm} \mathrm{Ca}{ }^{2+}(p=0.003)$. Endogenous calpain activity was increased when more $\mathrm{Ca}^{2+}(10 \mathrm{~mm})$ was added $(p=0.003)$. Quantification of assay intensity is expressed as arbitrary fluorescence units versus time. The asterisk $\left(^{*}\right)$ symbols show significant difference between two conditions tested for significance by paired Student's $t$ test. Differences were considered significant if $p<0.05$.

\section{LFD is abolished by calpain inhibition in vivo}

LFD recorded from intact preparations was also inhibited by calpain inhibitors MDL 28170 (Fig. 6A) and PD 150606 (Fig. 6B), but not by the inactive control compound PD 145305 (Fig. 6C) $(n=5)$.

Calpain activity is modulated by $\mathrm{Ca}^{2+}$ and calpain inhibitors To examine calpain activity, we used a fluorimetric assay based on a FRET-substrate peptide for calpain (Fig. 7). Proteolytic cleavage of 5-FAM/QXL 520 FRET peptide by calpain was observed in four independent CNS protein lysates after $30 \mathrm{~min}$ incubation under various conditions: extract + peptide substrate + EGTA; extract + peptide substrate + calpain inhibitor I; extract + peptide substrate; extract + peptide substrate $+100 \mu \mathrm{M}$ $\mathrm{CaCl}_{2}$; extract + peptide substrate $+10 \mathrm{mM} \mathrm{CaCl}^{2+}$ calpain inhibitor I; extract + peptide substrate $+10 \mathrm{~mm} \mathrm{CaCl}_{2}$. Various isoforms of calpain have various sensitivities to calcium (mcalpain from human is activated by millimolar $\mathrm{Ca}^{2+}$ concentrations, while $\mu$-calpain is activated by micromolar $\mathrm{Ca}^{2+}$ concentrations (Goll et al., 2003); therefore, we tested a wide range of calcium concentrations for their effects on calpain activity (Zhu et al., 2009).

When we stimulated calpain by addition of $100 \mu \mathrm{M} \mathrm{CaCl}_{2}$, the enzyme activity increased compared with the control (peptide + extract) that had only the endogenous $\mathrm{Ca}^{2+}$ released from breaking the cells $(p=0.022)$ and the control in which $\mathrm{Ca}^{2+}$ was removed by chelation with EGTA $(p=0.002)$, confirming $\mathrm{Ca}^{2+}$ dependence of calpain in our system. In contrast, incubation in the presence of inhibitor I reduced calpain activity when no additional $\mathrm{Ca}^{2+}$ was present $(p=0.002)$ and when additional $\mathrm{Ca}^{2+}$ was added $(10 \mathrm{~mm})(p=0.003)$. Endogenous calpain activity was greater when more $\left.\mathrm{Ca}^{2+}(10 \mathrm{mM})(p=0.003)\right)$ or protein extract was added (data not shown).

\section{Calcineurin A is present at nerve terminals}

We previously showed that crayfish neuromuscular junctions contain immunoreactivity similar to that of calcineurin B (SilvermanGavrila et al., 2005). To determine whether calcineurin A is present at the presynaptic terminals of crayfish, we used immunocytochemistry and double immunostained for calcineurin A (Fig. 8Ab) and syntaxin (a presynaptic compartment marker) (Fig. 8Aa). Calcineurin A immunoreactivity was evident at both phasic and tonic terminals. Calcineurin A immunoreactivity at the boutons appears to colocalize with syntaxin (Fig. 8Ac). Western blot analysis showed that anti-calcineurin A antibody recognized a single protein band of $\sim 67 \mathrm{kDa}$ in crayfish nerve cord and presynaptic processes (Fig. $8 B$ ), demonstrating that the antibody has appropriate specificity.

\section{Calcineurin A is cleaved by calpain}

Amino acid sequence comparison between the closely related Decapoda (Astacidae) crustacean Homarus americanus (lobster), Drosophila, and human calcineurin shows that calcineurin A is highly conserved among species (Fig. 8C). Most importantly, the cleavage sites required for calpain to produce constitutively active calcineurin are identical in human and lobster. Owing to the close phylogenetic relationship between lobster and crayfish and the high degree of conservation of the amino acid sequence, we assume that the crayfish sequence is very similar to that of lobster.

We used immunoblotting to detect calpain-mediated proteolysis of calcineurin A in CNS lysates. Generation of a $47 \mathrm{kDa}$ fragment of calcineurin A-the constitutively active form of calcineurin-was detected after $5 \mathrm{~min}$ in the presence of $\mathrm{Ca}^{2+}$ but was minimal in the presence of $\mathrm{Ca}^{2+}$ and calpain inhibitors or $\mathrm{Ca}^{2+}$-free conditions after $15 \mathrm{~min}$ (Fig. 8D,E), suggesting that calpain partially cleaves calcineurin A.

\section{LFD inhibition by calpain inhibitors causes changes in actin and tubulin cytoskeleton at phasic terminals}

In a previous study we showed, by phosphoproteomics, that LFD is accompanied by decreases in phosphoactin and phosphotubulin. These decreases required active calcineurin and did not occur in the presence of FK 506 (Silverman-Gavrila and Charlton, 2009, their Fig. 4e). During LFD, phosphoactin immunoreactivity in the synaptic terminals decreases by $\sim 40 \%$ as shown by Western blotting from presynaptic processes (Fig. $9 A, B$ ) and by $70 \%$ as shown by immunostaining (Fig. $9 C, D, F$ ). Calpain inhibitor I application not only prevented the decrease of phosphoactin but even increased it at the boutons as seen by immunostaining (Fig. $9 E, F)$. The actin level measured by Western blotting did not change, suggesting that calpain did not have a direct effect on actin in these experiments.

A decrease in immunoreactivity of polymerized tubulin was also observed during LFD (Silverman-Gavrila and Charlton, 2009, their Fig. 7c). Here we asked whether calpain activity is also required to regulate the cytoskeleton in LFD. We wanted to know if the inhibition of LFD by inhibition of calpain abrogates the changes in the cytoskeleton usually seen in LFD. We therefore double stained for tubulin and actin after LFD inhibition with calpain inhibitor I and found that tubulin was increased at phasic 

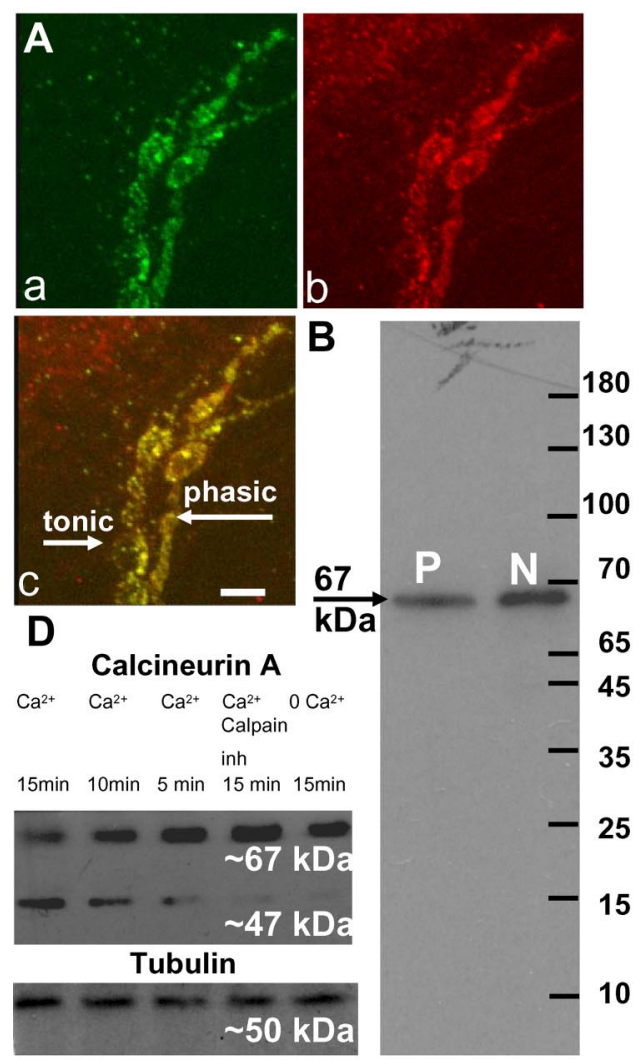

\section{Calcineurin A}

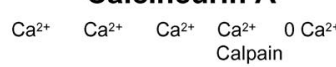

$15 \min 10 \mathrm{~min} 5 \mathrm{~min} 15 \mathrm{~min} 15 \mathrm{~min}$
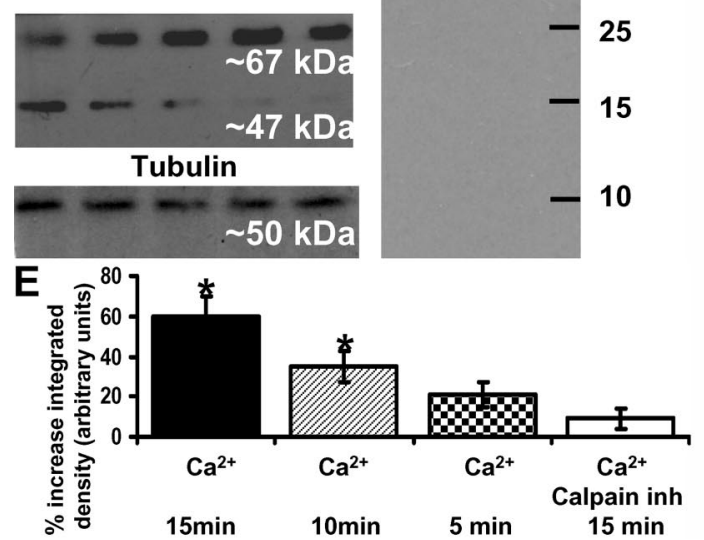

C Human $\alpha$

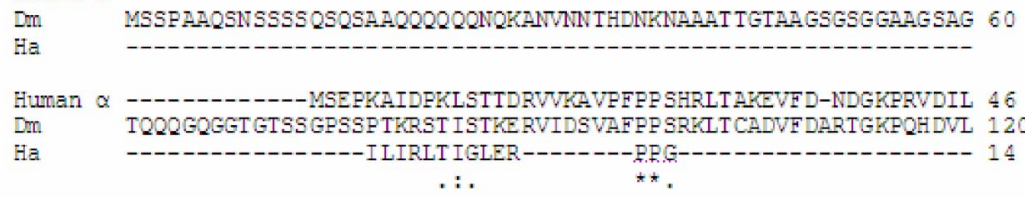

Fuman $\alpha$ KAHLMKEGRLESVALRI ITEGASILRQEKNLLDIDAPVTVCGDIHGOFFDLMKLFEVGG 106 Dm KQHF ILEGR IEESAALRI IQEGA TLLRTEKTMI DIEAPVTVCGDIHGOFYDLMKLFE IGG 180

Ha QVHF ILEGR IDEARALRI INEGA_LLRQEKTMI DIEAPVTVCGDIHGQ FYDLMKLFEVGG 74

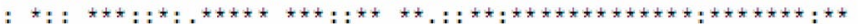

Human $\alpha$ SPANTRYL LGDYVDGY FSIECVIYLWALILYPKTL FLLRGNHECRHLTEY FTFKQEC 166 Dm. SPAT TKYL F LGYVDRGY FSIECVLYLWSLKIT YPOTL FLLRGNHECRHLTEY FT FKOEC 240 $\mathrm{Ha}$ PFNCTKYLFLGDVDRGY FSIECVLYLWIKICYPNTL FLLRGNHECRHLTEY FTFKOEC 134 FNCTKYL LGDYVRGY FSIECVLYLWALICYPNTL FLLRGNHECRHLTEY FTFKQEC 134

Human $\alpha$ KIKYSERVYDACMDAFDCLPLARIMNOQFLCVHGGLSPEINTLDDIRKLDRFKEPPAYGP 226 Dm KIKY SERYYDACMDAFDCLPLARMMOOFLCVHGGLSPEIHELEDIRRLDRFKEPPAFGP 300 Ha RIKYSERVYDACMEAFDCLPLARLMNOFLCVHGGLSPELHTLDDIRKLDRFKEPPAFGP 194

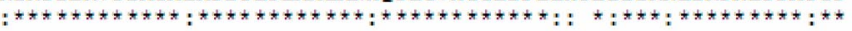

Human $\alpha$ MCDI LWSDPLEDF GNEKT QEHFT HNTVRGCSYFYSYPAVCEFLOHNLLSILRAHEAODA 286 Dm MCDLLWSDPLEDFGNEKN SDFYT HNSVRGCSYFYSYAACCDFLONNNLLSIIRAHEAQDA 360 Ha MCDILWSDPLEDFGNEMAEHESHNSVRGCSYFYSYAACCDFLQHNILSIIRAHEAQDA 254

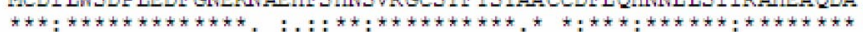

Human $\alpha$ GYRMYRKSQTIGF PSLITIFSAPNYLDVYNNKA.AVLKYEMNMNIRQFNCSPH PYWL FNE 346 Dm GYRMYRKSOTIGF PSLIT IFSAPNYLDVYNNKA.AVLKYENNMANIRQFNCSPH PYWL FNF 420 Ha GYRMYRSOTTGF PSLITIFSAPNYLDVYNNKA.AVLKYENWMNIROFNCSPH PYWL PNF 314 tt

Human $\alpha$ MDVF TWSLP FVGEKTEMLWNLNICSDDELGS--EEDGFDGATAPARKEVIRNKIRAIG 404 Dm MDVE TWSLP FVGEKVTEMLVNLNICSDDELMTEESEE PLSDDEAPLRKEVIRNKIRAIG 480 Ha MDVF TWSLP FVGEWTEMLMNLNICSDDELMD--GEESLDEEKGPMRKEVIRNKIRAIG 372

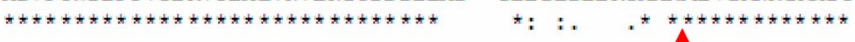

Human $\alpha$ KMRVFSVLRESESVLTLKGLTPT GLPSGVSGGKQTLQSATVEAIEADEAIKGFSPQ 464 Dm KMARVFSVLREESESVLQLKGLTPT GALPL GALSGGKQSLKN----------AMQGFSPN 530

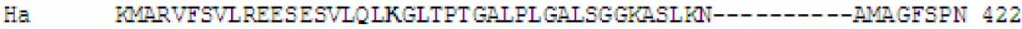

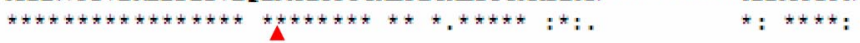

Human $\alpha$ HKIT SFEEAKGLDRINERMPPRRDAMPSDANLNSINKALISETNGTDSNGSNSSNIQ 521 $\mathrm{Dm}$ HKIT SFAEAKGLDAMNERMPPRRDATPS PA--EEGQKS LSAAADAAANANANS ING- 584 HKIT SFAEAKGLDAMNERM--Hitis

Figure 8. Calcineurin A is present at crayfish phasic and tonic terminals and is cleaved by calpain. $A$, Double immunostaining confocal images showing the presence of calcineurin $A(b$, red) at both phasic and tonic boutons and its distribution relative to the presynaptic membrane marker syntaxin ( $\boldsymbol{a}$, green). $\boldsymbol{c}$, Overlay image of $\boldsymbol{a}$ and $\boldsymbol{b}$, colocalization (yellow). Bar, $4 \mu \mathrm{m}$. $\boldsymbol{B}$, Western blot analysis showed that anti-calcineurin A antibody recognized a single protein band of $\sim 67 \mathrm{kDa}$ (arrow) in crayfish nerve cord (N) and in presynaptic processes (P). C, Comparison of amino acid (aa) sequence of lobster Homarus americanus (Ha) calcineurin A with those of the human calcineurin isoform $\alpha$ (gi|1352673|sp|Q08209.1) and Drosophila melanogaster (Dm) calcineurin (GenBank: AFH07430.1) aligned by (lusta 2.1. The deduced aa sequences were aligned, and the aa residues that are identical for all are highlighted with an asterisk (*), those that are similar have a colon (:), and those that are less similar are shown with a dot $(\cdot)$. Lobster calcineurin is highly homologous to human calcineurin. The calpain cleavage sites at position 392 and 424 of human calcineurin (Wu and Lynch, 2006) are indicated by red arrowheads and are identical in Homarus and Drosophila calcineurin. $\boldsymbol{D}, \boldsymbol{E}$, Western blot analysis for calcineurin A cleavage by calpain (D). Representative immunoblot and quantification of protein levels $(\boldsymbol{E})$ show an increase in immunoreactivity of cleaved proteins at $47 \mathrm{kDa}$ in $10 \mathrm{~mm} \mathrm{Ca}^{2+}$ conditions but minimal in the presence of $10 \mathrm{~mm} \mathrm{Ca}^{2+}+\mathrm{Calpain}^{2}$ inhibitor I or $\mathrm{Ca}^{2+}$ free conditions. Calpain-dependent production of the of $47 \mathrm{kDa}$ fragment was detected in the presence of $10 \mathrm{~mm} \mathrm{Ca}{ }^{2+}$ after $5 \mathrm{~min}$ and increased by $\sim 30 \%$ after $10 \mathrm{~min}$ and $\sim 60 \%$ after 15 min relative to calcium-free conditions at $15 \mathrm{~min}(n=3)$. Immunoblotting with anti-tubulin showed an equal amount of loaded protein in each lane. The asterisk $\left({ }^{*}\right)$ symbol indicates a significant difference compared to the calcium free condition (Student's $t$ test, $p<0.05$ ).

terminals (Fig. $10 D, E$ ) as compared to control preparations treated with calpain inhibitor I (control for calpain activity unrelated to LFD) (Fig. $10 B, E$ ) or the preparations after LFD (Fig. $10 C, E)$ or unstimulated preparations in which calpain would not be activated by $\mathrm{Ca}^{2+}$ influx during stimulation (control for calpain activation) (Fig. $10 \mathrm{~A}, \mathrm{E}$ ). Therefore, the usual decrease in tubulin reactivity induced during LFD did not occur. There was no increase of tubulin in tonic terminals or changes in actin immunoreactivity that could be detected at this level of resolution.

Calpain, calcineurin, and other regulators of phosphorylation are not involved in high-frequency depression

Since these results point to a specific pathway that involve calcineurin, calpain, and other phosphorylation-related events, we next asked whether other forms of depression in these synapses, such as high-frequency depression (HFD) (Bradacs et al., 1997), depend on a similar mechanism. Stimulation at $20 \mathrm{~Hz}$ caused a fast potentiation $(60 \%)$ of transmitter release followed by a rapid depression $(n=4)$ (Fig. $11 A)$ that recovered quickly when the frequency of stimulation was reduced to $0.2 \mathrm{~Hz}$ (data not shown). The recovery from high-frequency depression was little affected by the $0.2 \mathrm{~Hz}$ stimulation that causes LFD, probably because the time course of recovery is very rapid compared to the development of LFD. The phosphatase inhibitors FK-506 (40 $\mu \mathrm{M})(n=$ 5) (Fig. $11 B$ ) and permeant calcineurin autoinhibitory peptide $(50 \mu \mathrm{M})(n=5)$ (Fig. $11 C)$ and the kinase inhibitors staurosporine $(10 \mu \mathrm{M})(n=4)$ (Fig. $11 D)$ and OA $(10 \mu \mathrm{M})(n=4)$ (Fig. $11 E)$, applied $10 \mathrm{~min}$ before stimulation, and calpain inhibitor I $(100 \mu \mathrm{M})$ applied $30 \mathrm{~min}$ before stimulation (Fig. 11F), did not affect the pattern of HFD. Previously we showed that the increase in the basal transmission at $0.0016 \mathrm{~Hz}$ after OA (by $\sim 50 \%$ ), Fk-506 (by $\sim 15 \%$ ), and permeant autoinhibitory peptide (by 

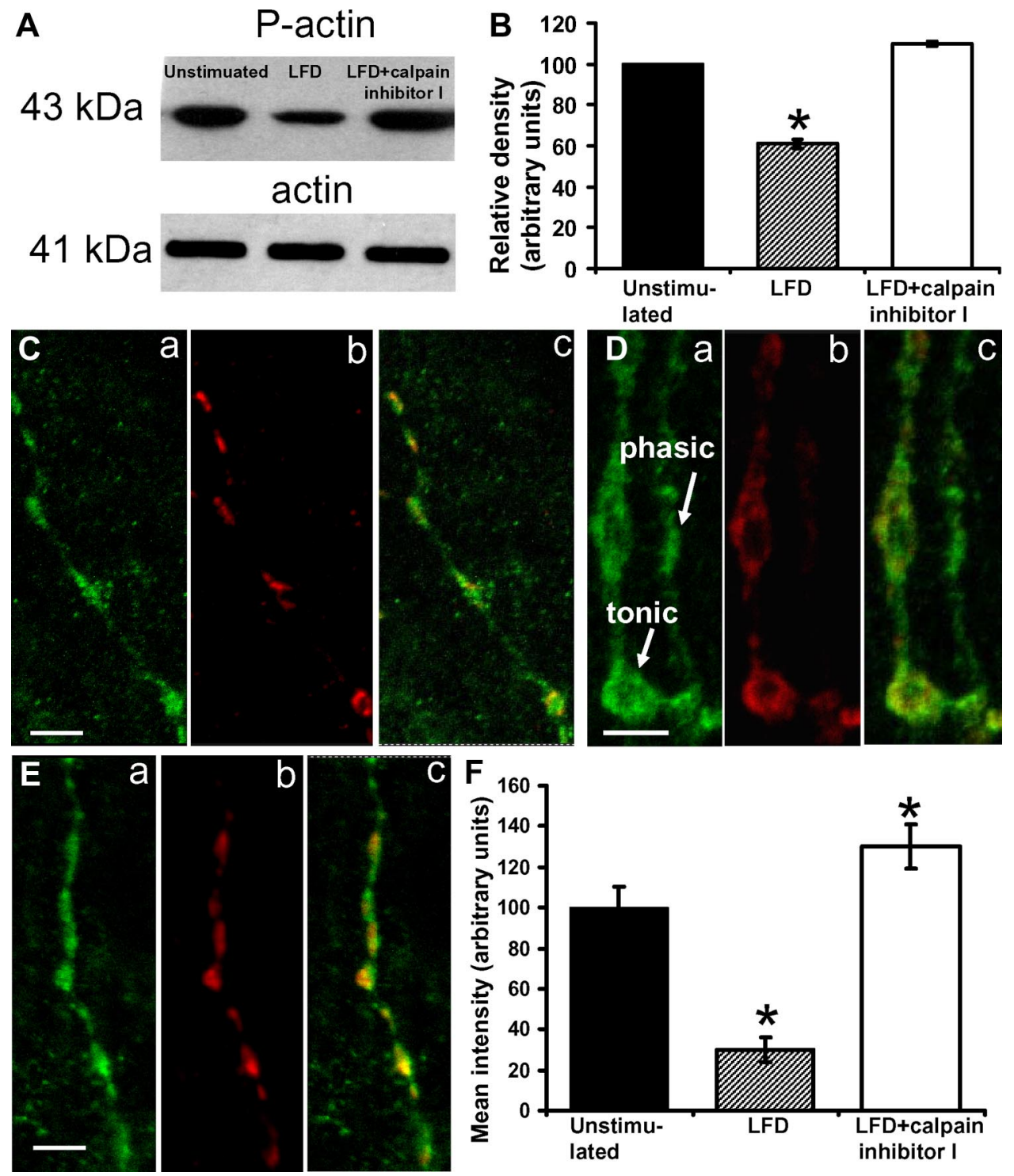

Figure 9. Inhibition of calpain prevents the decrease of phospho-actin in LFD. A. B, Representative Western blotting for P-actin (43 kDa band) and actin (41 kDa band) ( $A$ ) and summary of phosphoactin levels from unstimulated and untreated controls, preparations stimulated for LFD, and preparations stimulated at $0.2 \mathrm{~Hz}$ and treated with calpain inhibitor I $(n=3)(\boldsymbol{B})$. The asterisk ${ }^{*}$ ) symbol indicates a significant difference (Student's $t$ test, $p<0.05$ ) showing that phosphoactin level decreased by $\sim 40 \%$ during stimulation for LFD and was reversed by calpain I inhibitor treatment at a level comparable to that of untreated and unstimulated controls. Immunoblotting with anti-actin showed an equal amount of loaded protein in each lane. $\boldsymbol{C}-\boldsymbol{E}$, Representative double immunostaining confocal images for syntaxin $(\boldsymbol{a}$, green) and its distribution relative to phosphoactin $(\boldsymbol{b}$, red) at phasic terminals from unstimulated and untreated preparations $(\boldsymbol{C})$, preparations stimulated at $0.2 \mathrm{~Hz}$ for $60 \mathrm{~min}(\boldsymbol{D})$, and preparations stimulated at $0.2 \mathrm{~Hz}$ and treated with calpain inhibitor I (E). In overlay images (c) yellow represents colocalization. Bars, $4 \mu \mathrm{m}$. Phosphoactin level is reduced by $\sim 70 \%$ during stimulation for LFD $(\boldsymbol{D} \boldsymbol{b})$; however, calpain I inhibitor application not only inhibits the decrease but actually causes an increases of phosphoactin levels by $\sim 30 \%$ $(\boldsymbol{E} \boldsymbol{b})$, as seen also in the summary of quantification of the phosphoactin levels from unstimulated and untreated controls, preparation stimulated for LFD, and preparation stimulated at $0.2 \mathrm{~Hz}$ and treated with calpain inhibitor I $(\boldsymbol{F})(n=3$ for each experimental condition). The asterisk $(*)$ symbol indicates a significant difference (Student's $t$ test, $p<0.05)$.

20\%) was stabilized after about 10 min (Silverman-Gavrila et al., 2005). Therefore, effects of these drugs on basal release were stable when we applied the high-frequency stimulation.

Since calpain and calcineurin inhibitors and other phosphorylation regulator drugs had little or no effect on HFD, unlike in LFD, changes in the phosphorylation state of proteins are not the major determinant of HFD where additional mechanisms must be involved.

\section{Discussion}

LFD is a physiological process

LFD $(0.2 \mathrm{~Hz})$ was discovered in isolated NMJ preparations (Silverman-Gavrila et al., 2005) bathed in a simple physiological saline. To examine whether LFD might be related to insufficiency of the physiological saline or lack of oxygenation, we recorded
EMGs in live animals and found that LFD occurs in vivo; this result rules out experimental problems of excised NMJ preparations as a cause of LFD. Moreover, LFD in vivo has pharmacological characteristics similar to those of dissected preparations. Thus, LFD is a physiological process. Previous recordings of EMGs from leg extensor muscles in freely moving crayfish showed that the phasic synapses were used rarely and at the beginning of locomotion (Bradacs et al., 1997), while other recordings detected no phasic activity (Chikamoto et al., 2008). Therefore, the normal activity of crayfish seems not to require continued activity of phasic synapses.

In several respects, LFD at crayfish synapses resembles homosynaptic depression in Aplysia synapses (Dousseau et al., 2010). 

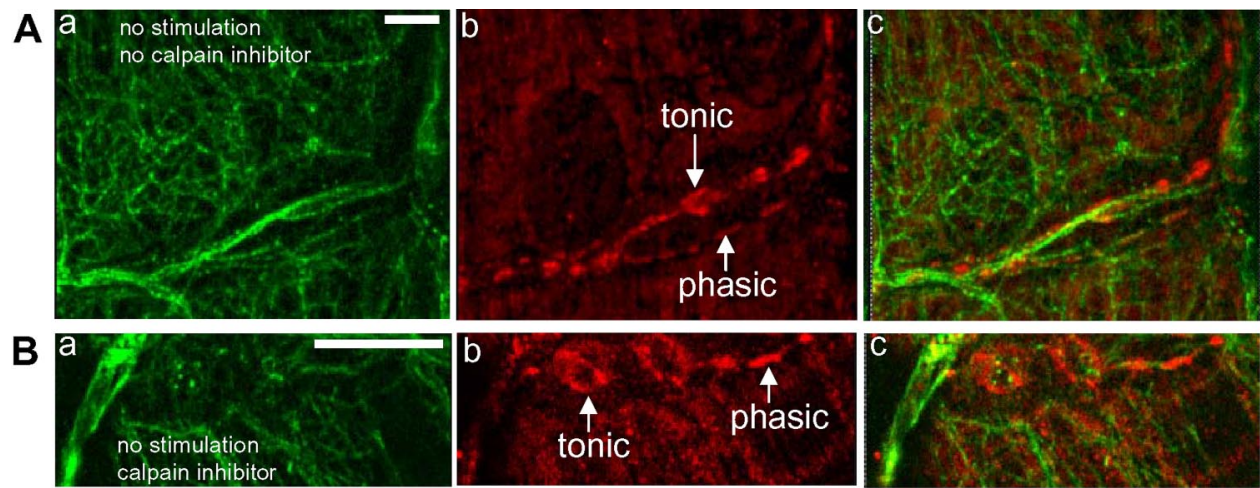

C a
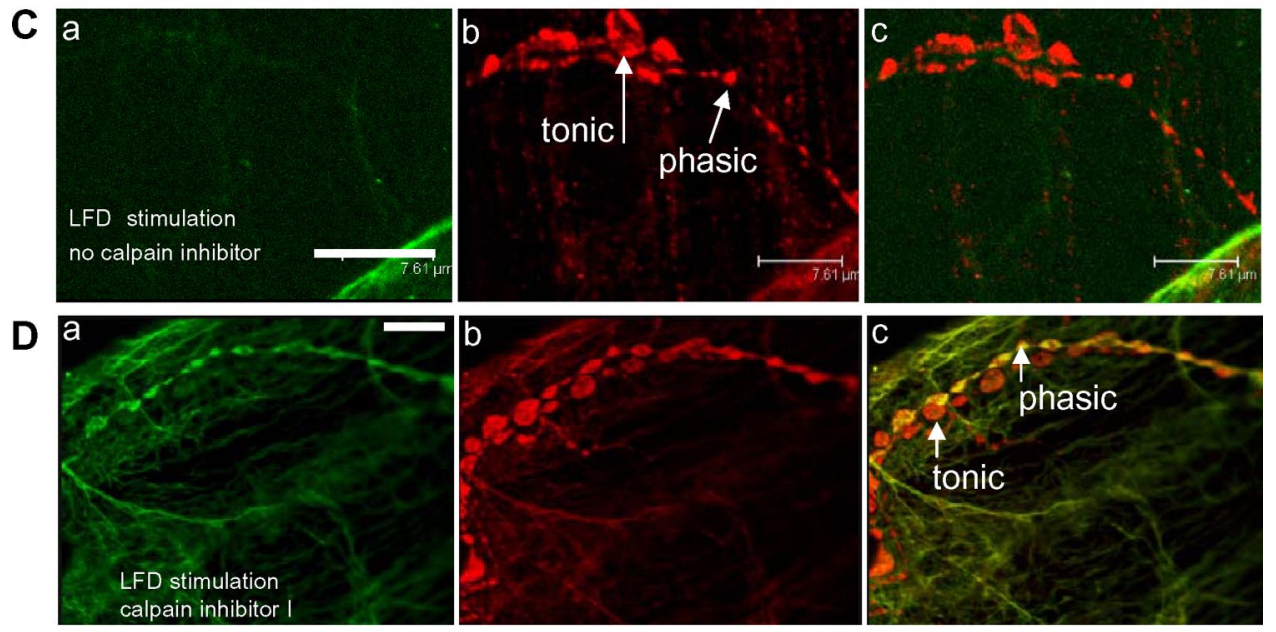

E
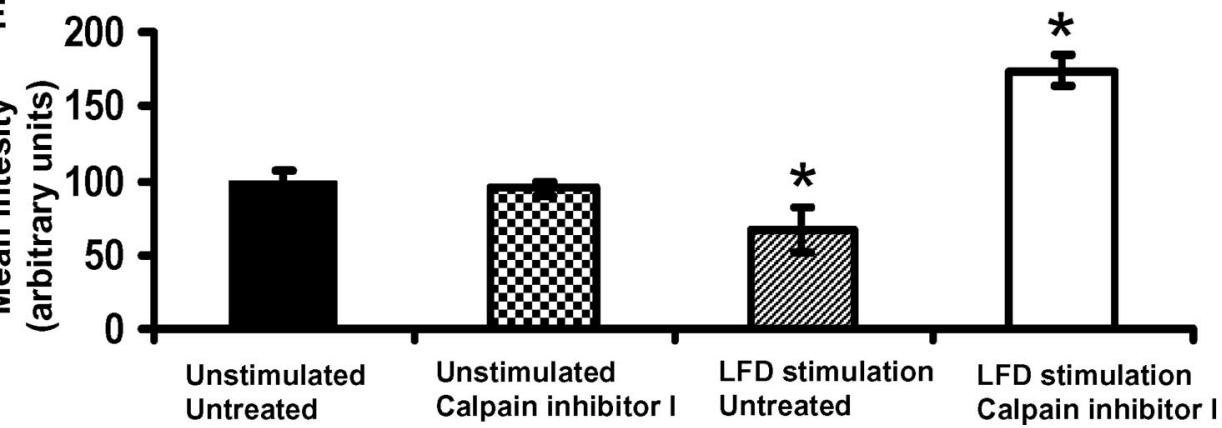

Figure 10. Inhibition of calpain prevents loss of tubulin immunoreactivity in LFD. $\boldsymbol{A}-\boldsymbol{D}$, Double-immunostaining confocal images showing the presence of tubulin ( $\boldsymbol{a}$, green) and its distribution relative to actin $(\boldsymbol{b}$, red) at terminals. In overlay images $(\boldsymbol{c})$, yellow represent colocalization. $\boldsymbol{A}-\boldsymbol{E}$, Compared to unstimulated preparations (control for calpain activation) $(\boldsymbol{A}, \boldsymbol{E})$ and preparations treated with calpain inhibitor I (control for calpain activity unrelated to LFD) ( $\boldsymbol{B}, \boldsymbol{E})$, LFD causes a decrease in tubulin intensity by $\sim 40 \%$ (C, $\boldsymbol{E}$ ) while LFD inhibition by inhibiting calpain with calpain inhibitor I causes an increase of $\sim 50 \%$ in tubulin at phasic boutons $(\boldsymbol{D}, \boldsymbol{E})$. Bars, $10 \mu \mathrm{m}$. $\boldsymbol{E}$, Summary of quantification of the tubulin intensity normalized to the untreated and unstimulated preparations ( $n=3$ for each experimental condition). The asterisk $\left(^{*}\right)$ symbol indicates a significant difference (Student's $t$ test, $p<0.05$ ).

Residual bulk $\mathrm{Ca}^{2+}$ does not activate LFD

During LFD the phosphorylation/dephosphorylation balance is tilted toward enhanced dephosphorylation by protein phosphatases $1 \mathrm{~A}, 2 \mathrm{~A}$, and 3 activity and/or relatively slower or reduced kinase activity such as $\mathrm{Ca}^{2+}$-stimulated kinase PKC or CaMKII that is present at the terminals (data not shown). Recovery from LFD requires kinase activity (Silverman-Gavrila et al., 2005). Our data from $\mathrm{Ca}^{2+}$ buffering experiments do not support the idea that presynaptic residual $\mathrm{Ca}^{2+}$ continually activates calcineurin during LFD, since slow $\mathrm{Ca}^{2+}$ chelators did not inhibit LFD. This agrees with previous results showing that the addition of moderate concentrations of mobile cytoplasmic $\mathrm{Ca}^{2+}$ chelators is insufficient to block transmitter release totally (Winslow et al., 1994; Tang et al., 2000; Zamir and Charlton, 2006). In contrast, reduced short-term synaptic enhancement, such as facilitation and augmentation, was observed by reducing residual presynaptic
$\mathrm{Ca}^{2+}$ accumulation with EGTA after neuronal activity (Zucker and Regehr, 2002; Zhong and Zucker, 2004). However, the fast $\mathrm{Ca}^{2+}$ chelator BAPTA inhibited LFD in our experiments. The effect of BAPTA-AM to block transmitter release was much greater at the tonic synapses of the opener muscle (Winslow et al., 1994) than at the phasic synapses of the extensor muscle (present data). This disparity is likely due to the tenfold higher sensitivity to $\mathrm{Ca}^{2+}$ in the phasic synapses than in the tonic synapses (Millar et al., 2005). BAPTA injected postsynaptically in motor neurons blocks the induction of LTD, but not that of short-term synaptic depression in Aplysia (Lin and Glanzman, 1996). Thus, it is unlikely that residual $\mathrm{Ca}^{2+}$ causes LFD by continual activation of calcineurin. The $\mathrm{Ca}^{2+}$ sensor may be closely associated with $\mathrm{Ca}^{2+}$ channels (Lukyanetz, 1997; Santana et al., 2002; Loane et al., 2006; Tandan et al., 2009), where it would receive a large, brief $\mathrm{Ca}^{2+}$ signal. Several reports show special subcellular domains for 
calcineurin (for review, Sanderson and Dell'aqua, 2011; Heineke and Ritter, 2012). Calcineurin is unlikely to be the only sensor, because $\mathrm{Ca}^{2+}$ binding on the B subunit has a $K_{\mathrm{d} 1}$ of $15 \mu \mathrm{M}$ that exceeds $\left[\mathrm{Ca}^{2+}\right]$ between stimuli. The intracellular concentration of EGTA and BAPTA obtained with application of EGTA-AM and BAPTA-AM is difficult to measure, since they only fluoresce with short UV excitation and emission. It is difficult to estimate concentrations because of variability of membrane permeability, esterase activity, accumulation in intracellular stores, and extrusion rates between cell types (Tsien, 1981; Van Der Zee et al., 1989; Di Virgilio et al., 1990; Munsch and Deitmer, 1995; Ouanounou et al., 1996). However, Negulescu et al. (1989) found that with $10 \mu \mathrm{M}$ BAPTA-AM, [BAPTA] rose to about $450 \mu \mathrm{M}$.

\section{Activation of calcineurin by calpain}

Calpain-like immunoreactivity at crayfish nerve terminals was disclosed using an antibody against lobster calpain $(60 \%$ similarity to human $\mathrm{m}$-calpain, $\mathrm{Yu}$ and Mykles, 2003). Calpain-like immunoreactivity was localized in the motor terminal region in lobster claw muscle (Medler et al., 2007). Invertebrate calpains share essential biochemical properties with mammalian calpains (Yu and Mykles, 2003; Kim et al., 2005). Two calpain-like $\mathrm{Ca}^{2+}$ dependent cysteine proteinases have been identified in lobster (Beyette et al., 1997).

The presynaptic $\mathrm{Ca}^{2+}$ signal could be decoded by calpain and the consequent proteolysis could increase calcineurin activity constitutively (Wang et al., 1989). It is possible that membrane localization of calpain (Leloup et al., 2010) could ensure its activation by a large $\mathrm{Ca}^{2+}$ signal near channels. While we do not have the amino acid sequence of crayfish calcineurin, the sequence of lobster calcineurin is highly similar to that of human and Drosophila calcineurin. Figure $8 C$ shows that the cleavage sites for calpain on calcineurin A are identical in human (Wu et al., 2004; Wu and Lynch, 2006), lobster, and Drosophila and that calpain activity produces a fragment with the molecular weight (MW) appropriate for the constitutively active phosphatase (Fig. 8D). The production of constitutively active calcineurin A has been demonstrated in neural tissue (Wu et al., 2004, Shioda et al., 2007) and cardiac tissue (Burkard et al., 2005), but its significance in presynaptic plasticity has not been described previously. Constitutively active calcineurin of mammals (Wu et al., 2004; Shioda et al., 2007) and Drosophila (Dr. Pascale Djikers, Department of Cell Biology, University Medical Center Groningen, The Netherlands, personal communication) can still be inhibited by FK 506, a drug that blocks LFD (Silverman-Gavrila et al., 2005). Calpain activity in CNS extract was $\mathrm{Ca}^{2+}$ dependent and cleaved calcineurin into a fragment with an MW appropriate for the constitutively active form of calcineurin (Fig. $8 D$ ).

The production of the constitutively activated form of calcineurin in vitro indicates that targeted proteolysis of calcineurin autoinhibitory domain by calpain could occur in nerve terminals. We have not demonstrated directly the stimulus-dependent production of
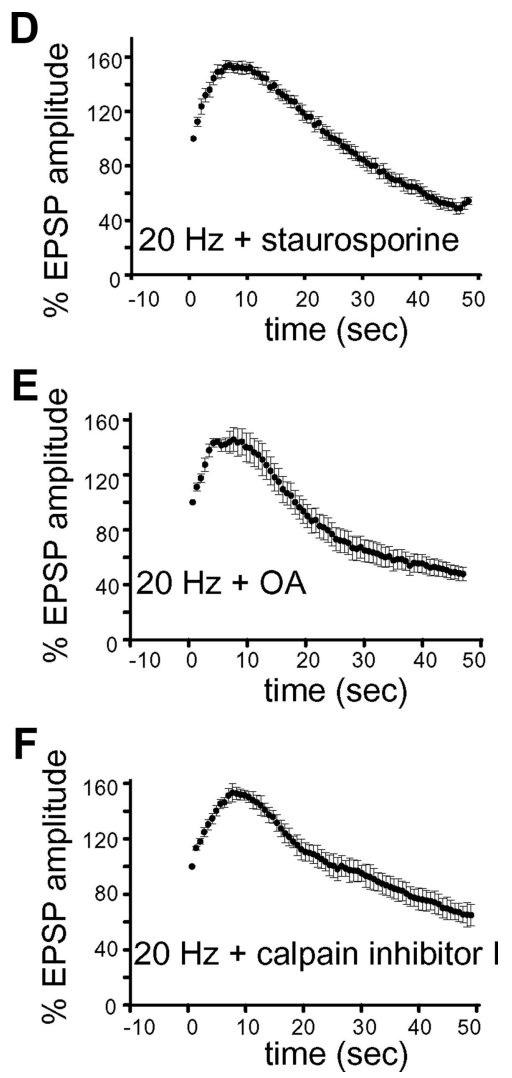

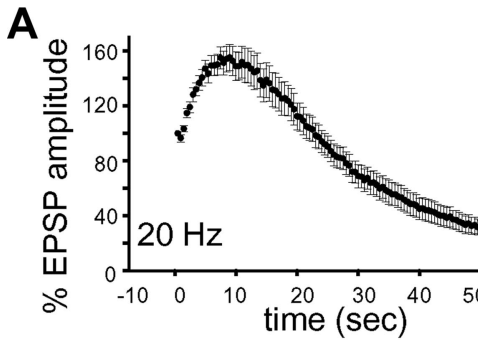

Figure 11. High-frequency $(20 \mathrm{~Hz})$ depression does not require activation of calpain, kinases, or phosphatases. $\boldsymbol{A}$, Control recordings at $20 \mathrm{~Hz}$ show early potentiation by $\sim 60 \%$ followed by a rapid depression $(n=4)$. $\boldsymbol{B}$ - $\boldsymbol{D}$, Depression elicited by high-frequency stimulation at $20 \mathrm{~Hz}$ was not abolished by treatment with $40 \mu \mathrm{m} \mathrm{FK-506(B)}(n=5), 50 \mu \mathrm{m}$ permeant calcineurin autoinhibitory peptide $(\boldsymbol{C})(n=5), 10 \mu \mathrm{m}$ staurosporine $(\boldsymbol{D})(n=4)$, or $10 \mu \mathrm{m}$ okadaic acid, OA $(\boldsymbol{E})(n=4)$ applied 10 min before stimulation. $\boldsymbol{F}$, Calpain inhibitor I (100 $\mu \mathrm{m})$ applied $30 \mathrm{~min}$ before stimulation did not affect high-frequency depression $(n=5)$.

constitutively active calcineurin in nerve terminals; this is technically too difficult at present. Thus, the evidence implicating calpain in the generation of LFD is as follows: (1) inhibition of calpain blocks LFD in vivo and in vitro; (2) activity of calcineurin is required for LFD; (3) both calpain and calcineurin are found in nerve terminals; and (4) $\mathrm{Ca}^{2+}$-dependent activity of CNS calpain produces a fragment of calcineurin known to be constitutively active.

Calpain can also cleave CAIN, an endogenous inhibitor of calcineurin (Kim et al., 2002), and this would also increase calcineurin activity. Moreover, calpain can autoactivate (Suzuki et al., 1981), and this would give additional hysteresis.

\section{Calpain inhibition alters LFD effects on the cytoskeleton}

Since calpain and calcineurin have many substrates, it is difficult to identify the exact protein(s) that may be cleaved or dephosphorylated in LFD (for review, Wu and Lynch, 2006). For instance, calpain cleaves amphiphysin, a protein required for endocytosis (Wu et al., 2007).

One candidate is actin, and we showed that actin dephosphorylation occurs during LFD and is inhibited by calpain inhibitor I application. Although beyond the scope of this paper, it will be interesting to determine whether dephosphorylation affects the actin polymerization or actin turnover. Another candidate is tubulin, which we showed previously to be involved in LFD. Stimulation to produce LFD causes a decrease in tubulin immunoreactivity at the phasic terminals similar to the effect of the microtubule-depolymerizing agent nocodazole (Silverman-Gavrila and Charlton, 2009). In the presence of cal- 


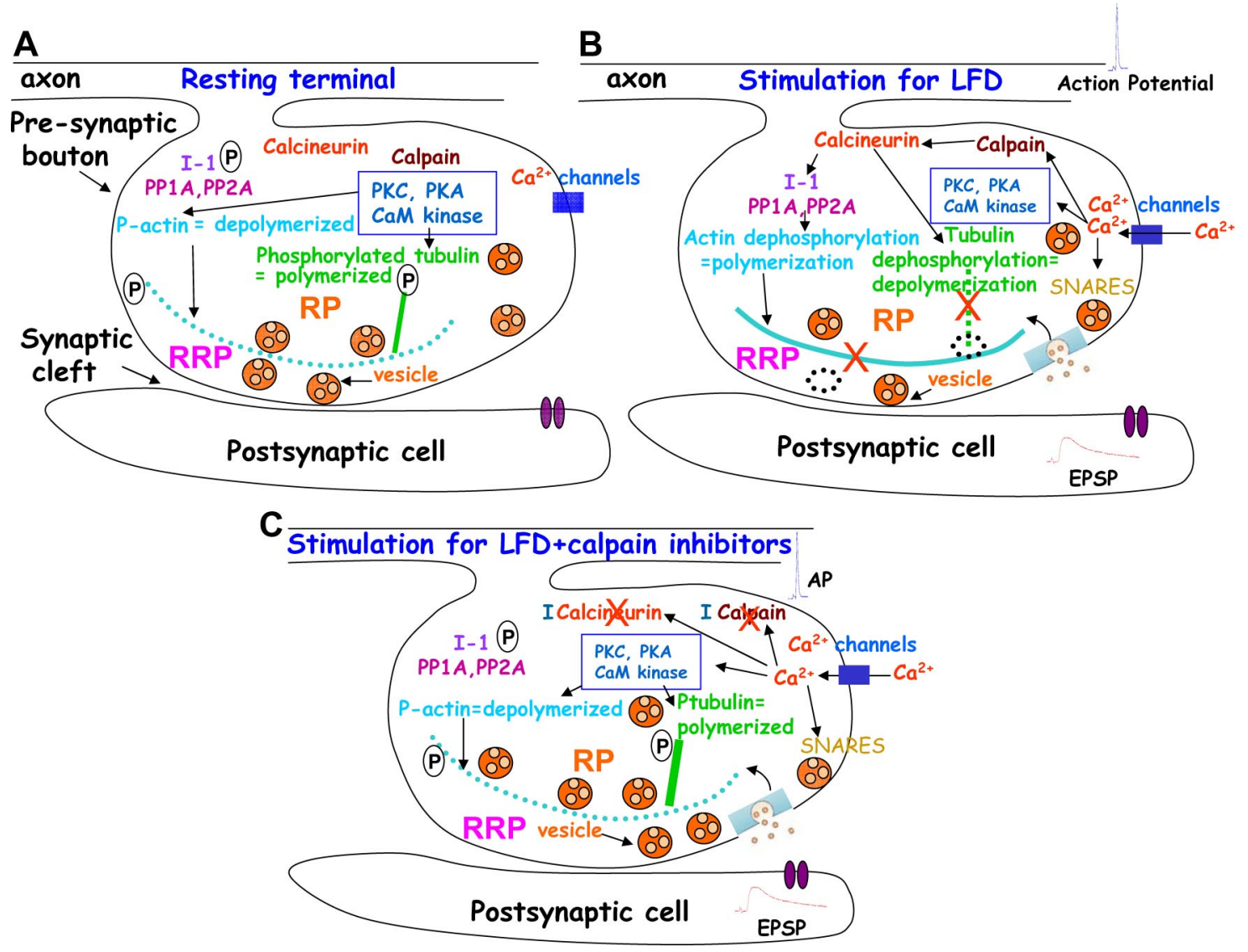

Figure 12. Diagram representing a speculative mechanism for regulation of LFD involving presynaptic calpain, calcineurin, cytoskeleton, and synaptic vesicles. $A$, Before depression, vesicles are transported to the reserve pool (RP) by tubulin (Schroer, 1992) that is phosphorylated by PKC, PKA (Silverman-Gavrila and Charlton, 2009), and CaM kinase (Yoshimura et al., 2000). At rest there is some kinase activity present. Actin phosphorylation causes actin depolymerization (Furuhashi, 2002), and therefore there is no barrier between the RP and the readily releasable pool (RRP) (Kuromi and Kidokoro, 1998). Tubulin phosphorylation causes polymerization of microtubules (MTs) (Serrano et al., 1987; Díaz-Nido et al., 1990) as tracks for vesicle transport to the RP (Schroer, 1992). $\boldsymbol{B}$, Low-frequency stimulation causes $\mathrm{Ca}^{2+}$ entry into the cell through $\mathrm{Ca}^{2+}$ channels, $\mathrm{Ca}^{2+}$ activates presynaptic calpain that cleaves and activates calcineurin. The balance is shifted toward dephosphorylation, even though other kinases such as CaM kinase might also be activated. Calcineurin activation dephosphorylates actin and tubulin (Silverman-Gavrila and Charlton, 2009). Calcineurin activates serine/threonine PP1 activity (Mulkey et al., 1994) by dephosphorylation and inactivation of Inhibitor-1 (I-1) which, in its phosphorylated form inhibits PP1 (Mulkey and Malenka, 1992; Mulkey et al., 1993; Mulkey et al., 1994; Kirkwood and Bear, 1994; for review, Malenka and Bear, 2004). Phospho-actin dephosphorylation by PP1 and PP2A (Fiorentini et al., 1996 ; Shtrahman et al., 2005) causes actin polymerization in a barrier that limits vesicle mobilization from RP to RRP holding the vesicles trapped in the RP during LFD and may restrain fusion of synaptic vesicle at the releasing site (Morales et al., 2000). Calcineurin dephosphorylates tubulin directly (Goto et al., 1985; Li and Handschumacher, 2002), causing depolymerization of MTs, and their disassembly during LFD potentially causes limitation of vesicle availability at RP for fusion. In consequence, vesicle trafficking on MT tracks to the RP is inhibited and cannot sustain cycling of synaptic vesicles. C, When calpain (I calpain) and/or calcineurin (I calcineurin) is inhibited, the phosphorylation balance is shifted toward phosphorylation, and kinases are activated and cause actin and tubulin phosphorylation that leads to actin depolymerization and tubulin polymerization that cause vesicle transport on MT and accumulation at RRP because the actin barrier between RP and RRP is disrupted. Increasing vesicle mobilization from the RP to RRP (Wang et al., 1996b; Ashton and Ushkaryov, 2005) by disrupting the barrier of actin (Kuromi and Kidokoro, 1998) will facilitate vesicle trafficking between RP and RRP and docking sites. Partial disassembly of actin filaments may facilitate vesicle transport within the terminal, and reassembly is necessary to limit that movement (Bernstein et al., 1998). In conclusion, LFD may in part be based on proteolytic regulation of calcineurin by calpain and assembly and disassembly of MT and actin filaments that control the equilibrium between the RP and RRP of synaptic vesicles, as well as their recycling.

pain inhibitors stimulation does not cause LFD, but there is an increase in tubulin at phasic synapses above that in control, unstimulated preparations. The microtubule stabilizer Taxol, which inhibited LFD, also increased tubulin immunoreactivity (Silverman-Gavrila and Charlton, 2009). It should be noted that it is the phosphorylation of tubulin that changes during LFD, and this affects tubulin polymerization (Wandosell et al., 1987) but not the total tubulin level (Silverman-Gavrila and Charlton, 2009, their Fig. 8g). Stimulation might activate both $\mathrm{Ca}^{2+}$ dependent phosphatases and kinases such as calcineurin and $\mathrm{Ca}^{2+} / \mathrm{CaM}$-dependent protein kinase. CaM kinases phosphorylate tubulin that is dephosphorylated by calcineurin (Goto et al., 1985; Wandosell et al., 1987), and calcineurin-B binds to tubulin in a $\mathrm{Ca}^{2+}$-dependent manner (Li and Handschumacher, 2002). The degree of tubulin polymerization depends on the relative rates of phosphorylation and dephosphorylation. Stimulation might activate tubulin dephosphorylation, therefore causing depolymerization, but when the activation of calcineurin is reduced by inhibition of calpain, kinase activity might predominate and cause an increase in phosphorylation and polymerization of tubulin. Microtubules may function as tracks for vesicle transport (Schroer, 1992) to the reserve pool. Changes in the microtubule cytoskeleton during LFD or treatment with microtubule affecting agents might suggest the involvement of microtubules in structural plasticity of presynaptic terminal during LFD (Becker et al., 2008). This implies that activation of tubulin polymerizability may be part of the mechanism of the second phase of LFD. Based on previous data (Silverman-Gavrila et al., 2005; SilvermanGavrila and Charlton, 2009) and the present results, we propose a model illustrated in Figure 12 in which high-amplitude $\mathrm{Ca}^{2+}$ 
signals cause sequentially calpain and consequently calcineurin activation. Modulation of actin and tubulin phosphorylation by calcineurin may modulate synaptic strength by affecting cytoskeleton polymerization (Silverman-Gavrila and Charlton, 2009).

Assembly and disassembly of microtubule and actin filaments may thus control the equilibrium between the reserve pool (RP) and the readily releasable pool (RRP) of synaptic vesicles and their recycling. $\mathrm{Ca}^{2+}$-activated and calcineurin-mediated dephosphorylation of actin and tubulin may provide a basis for a more general mechanism to regulate microfilament organization and may play a role in mediating some effects of $\mathrm{Ca}^{2+}$ on neuronal function by linking elevation of calcium to vesicle delivery to the sites of vesicle release and recycling.

This work demonstrates that presynaptic calpain has strong effects on transmitter release, some of which are mediated by activation of a phosphatase. Moreover, these effects occur during normal physiology rather than in the pathological conditions often associated with activation of calpain. The cleavage-induced activation of calcineurin by calpain might be a common mechanism in other forms of mammalian LTD where calcineurin is involved (Mulkey et al., 1993; Kirkwood and Bear, 1994; Li et al., 2002; Lin et al., 2003; Belmeguenai and Hansel, 2005; Morishita et al., 2005; Heifets et al., 2008; Lin et al., 2008). Crucial questions remain regarding how calpain activity is regulated and how substrate selection is achieved in neurons.

Synaptic plasticity mechanisms discovered in invertebrates have usually been confirmed in the mammalian CNS. Future experiments should determine whether other forms of depression in mammalian systems occur through a similar process.

\section{References}

Adler EM, Augustine GJ, Duffy SN, Charlton MP (1991) Alien intracellular calcium chelators attenuate neurotransmitter release at the squid giant synapse. J Neurosci 11:1496-1507. Medline

Araújo IM, Gil JM, Carreira BP, Mohapel P, Petersen A, Pinheiro PS, Soulet D, Bahr BA, Brundin P, Carvalho CM (2008) Calpain activation is involved in early caspase-independent neurodegeneration in the hippocampus following status epilepticus. J Neurochem 105:666-676. CrossRef Medline

Ashton AC, Ushkaryov YA (2005) Properties of synaptic vesicle pools in mature central nerve terminals. J Biol Chem 280:37278-37288. CrossRef Medline

Becker N, Wierenga CJ, Fonseca R, Bonhoeffer T, Nägerl UV (2008) LTD induction causes morphological changes of presynaptic boutons and reduces their contacts with spines. Neuron 60:590-597. CrossRef Medline

Belmeguenai A, Hansel C (2005) A role for protein phosphatases 1,2A, and 2B in cerebellar long-term potentiation. J Neurosci 25:10768-10772. CrossRef Medline

Bernstein BW, DeWit M, Bamburg JR (1998) Actin disassembles reversibly during electrically induced recycling of synaptic vesicles in cultured neurons. Brain Res Mol Brain Res 53:236-251. Medline

Beyette JR, Emori Y, Mykles DL (1997) Immunological analysis of two calpain-like $\mathrm{Ca}^{2+}$-dependent proteinases from lobster striated muscles: relationship to mammalian and Drosophila calpains. Arch Biochem Biophys 337:232-238. CrossRef Medline

Boehmerle W, Zhang K, Sivula M, Heidrich FM, Lee Y, Jordt SE, Ehrlich BE (2007) Chronic exposure to paclitaxel diminishes phosphoinositide signaling by calpain-mediated neuronal calcium sensor-1 degradation. Proc Natl Acad Sci U S A 104:11103-11108. CrossRef Medline

Borst JG, Sakmann B (1999) Depletion of calcium in the synaptic cleft of a calyx-type synapse in the rat brainstem. J Physiol 521:123-133. CrossRef Medline

Bougie JK, Lim T, Farah CA, Manjunath V, Nagakura I, Ferraro GB, Sossin WS (2009) The atypical protein kinase C in Aplysia can form a protein kinase M by cleavage. J Neurochem 109:1129-1143. CrossRef Medline

Bougie JK, Cai D, Hastings M, Farah CA, Chen S, Fan X, McCamphill PK,
Glanzman DL, Sossin WS (2012) Serotonin-induced cleavage of the atypical protein kinase C Apl III in Aplysia. J Neurosci 32:14630-14640. CrossRef Medline

Bradacs H, Cooper R, Msghina M, Atwood H (1997) Differential physiology and morphology of phasic and tonic motor axons in a crayfish limb extensor muscle. J Exp Biol 200:677-691. Medline

Burkard N, Becher J, Heindl C, Neyses L, Schuh K, Ritter O (2005) Targeted proteolysis sustains calcineurin activation. Circulation 111:1045-1053. CrossRef Medline

Chikamoto K, Kagaya K, Takahata M (2008) Electromyographic characterization of walking behavior initiated spontaneously in crayfish. Zoolog Sci 25:783-792. CrossRef Medline

Chiu K, Lam TT, Ying Li WW, Caprioli J, Kwong Kwong JM (2005) Calpain and $\mathrm{N}$-methyl-D-aspartate (NMDA)-induced excitotoxicity in rat retinas. Brain Res 1046:207-215. CrossRef Medline

Cooper RL, Warren WM, Ashby HE (1998) Activity of phasic motor neurons partially transforms the neuronal and muscle phenotype to a toniclike state. Muscle Nerve 21:921-931. CrossRef Medline

DeMill CM, Delaney KR (2005) Interaction between facilitation and presynaptic inhibition at the crayfish neuromuscular junction. J Exp Biol 208:2135-2145. CrossRef Medline

Díaz-Nido J, Serrano L, López-Otín C, Vandekerckhove J, Avila J (1990) Phosphorylation of a neuronal-specific beta-tubulin isotype. J Biol Chem 265:13949-13954. Medline

Di Virgilio F, Steinberg TH, Silverstein SC (1990) Inhibition of Fura-2 sequestration and secretion with organic anion transport blockers. Cell Calcium 11:57-62. CrossRef Medline

Doussau F, Humeau Y, Benfenati F, Poulain B (2010) A novel form of presynaptic plasticity based on the fast reactivation of release sites switched off during low-frequency depression. J Neurosci 30:16679-16691. CrossRef Medline

Fiorentini C, Matarrese P, Fattorossi A, Donelli G (1996) Okadaic acid induces changes in the organization of F-actin in intestinal cells. Toxicon 34:937-945. CrossRef Medline

Furuhashi K (2002) Involvement of actin dephosphorylation in germination of Physarum sclerotium. J Eukaryot Microbiol 49:129-133. CrossRef Medline

Godell CM, Smyers ME, Eddleman CS, Ballinger ML, Fishman HM, Bittner GD (1997) Calpain activity promotes the sealing of severed giant axons. Proc Natl Acad Sci U S A 94:4751-4756. CrossRef Medline

Goll DE, Thompson VF, Li H, Wei W, Cong J (2003) The calpain system. Physiol Rev 83:731-801. CrossRef Medline

Goto S, Yamamoto H, Fukunaga K, Iwasa T, Matsukado Y, Miyamoto E (1985) Dephosphorylation of microtubule-associated protein 2, tau factor, and tubulin by calcineurin. J Neurochem 45:276-283. CrossRef Medline

Heifets BD, Chevaleyre V, Castillo PE (2008) Interneuron activity controls endocannabinoid-mediated presynaptic plasticity through calcineurin. Proc Natl Acad Sci U S A 105:10250-10255. CrossRef Medline

Heineke J, Ritter O (2012) Cardiomyocyte calcineurin signaling in subcellular domains: from the sarcolemma to the nucleus and beyond. J Mol Cell Cardiol 52:62-73. CrossRef Medline

Hochner B, Parnas H, Parnas I (1991) Effects of intra-axonal injection of $\mathrm{Ca}^{2+}$ buffers on evoked release and on facilitation in the crayfish neuromuscular junction. Neurosci Lett 125:215-218. CrossRef Medline

Jouvenceau A, Dutar P (2006) Role for the protein phosphatase 2B in altered hippocampal synaptic plasticity in the aged rat. J Physiol Paris 99: 154-161. CrossRef Medline

Khoutorsky A, Spira ME (2005) Calcium-activated proteases are critical for refilling depleted vesicle stores in cultured sensory-motor synapses of Aplysia. Learn Mem 12:414-422. CrossRef Medline

Kilinc D, Gallo G, Barbee KA (2009) Mechanical membrane injury induces axonal beading through localized activation of calpain. Exp Neurol 219: 553-561. CrossRef Medline

Kim MJ, Jo DG, Hong GS, Kim BJ, Lai M, Cho DH, Kim KW, Bandyopadhyay A, Hong YM, Kim DH, Cho C, Liu JO, Snyder SH, Jung YK (2002) Calpain-dependent cleavage of cain/cabin1 activates calcineurin. CrossRef Medline

Kim HW, Chang ES, Mykles DL (2005) Three calpains and ecdysone receptor in the land crab Gecarcinus lateralis: sequences, expression and effects of elevated ecdysteroid induced by eyestalk ablation. J Exp Biol 208:31773197. CrossRef Medline 
Kirkwood A, Bear MF (1994) Homosynaptic long-term depression in the visual cortex. J Neurosci 14:3404-3412. Medline

Kuromi H, Kidokoro Y (1998) Two distinct pools of synaptic vesicles in single presynaptic boutons in a temperature-sensitive Drosophila mutant, shibire. Neuron 20:917-925. CrossRef Medline

Laval M, Pascal M (2002) A calpain-like activity insensitive to calpastatin in Drosophila melanogaster. Biochim Biophys Acta 1570:121-128. CrossRef Medline

Leloup L, Shao H, Bae YH, Deasy B, Stolz D, Roy P, Wells A (2010) $\mathrm{m}$-Calpain activation is regulated by its membrane localization and by its binding to phosphatidylinositol 4,5-bisphosphate. J Biol Chem 285: 33549-33566. CrossRef Medline

Li ST, Kato K, Tomizawa K, Matsushita M, Moriwaki A, Matsui H, Mikoshiba K (2002) Calcineurin plays different roles in group II metabotropic glutamate receptor- and NMDA receptor-dependent long-term depression. J Neurosci 22:5034-5041. Medline

Li W, Handschumacher RE (2002) Identification of two calcineurin B-binding proteins: tubulin and heat shock protein 60. Biochim Biophys Acta 1599:72-81. CrossRef Medline

Liang Z, Liu F, Grundke-Iqbal I, Iqbal K, Gong CX (2007) Down-regulation of cAMP-dependent protein kinase by over-activated calpain in Alzheimer disease brain. J Neurochem 103:2462-2470. CrossRef Medline

Lin CH, Lee CC, Gean PW (2003) Involvement of a calcineurin cascade in amygdala depotentiation and quenching of fear memory. Mol Pharmacol 63:44-52. CrossRef Medline

Lin GD, Chattopadhyay D, Maki M, Wang KK, Carson M, Jin L, Yuen PW, Takano E, Hatanaka M, DeLucas LJ, Narayana SV (1997) Crystal structure of calcium bound domain VI of calpain at 1.9 A resolution and its role in enzyme assembly, regulation, and inhibitor binding. Nat Struct Biol 539-547. Medline

Lin XY, Glanzman DL (1996) Long-term depression of Aplysia sensorimotor synapses in cell culture: inductive role of a rise in postsynaptic calcium. J Neurophysiol 76:2111-2114. Medline

Lin YW, Yang HW, Min MY, Chiu TH (2008) Inhibition of associative longterm depression by activation of beta-adrenergic receptors in rat hippocampal CA1 synapses. J Biomed Sci 15:123-131. CrossRef Medline

Lnenicka GA, Atwood HL (1985) Age-dependent long-term adaptation of crayfish phasic motor axon synapses to altered activity. J Neurosci 5:459467. Medline

Loane DJ, Hicks GA, Perrino BA, Marrion NV (2006) Inhibition of BK channel activity by association with calcineurin in rat brain. Eur J Neurosci 24:433-441. CrossRef Medline

Lukyanetz EA (1997) Evidence for colocalization of calcineurin and calcium channels in dorsal root ganglion neurons. Neuroscience 78:625-628. CrossRef

Majumder P, Raychaudhuri S, Chattopadhyay B, Bhattacharyya NP (2007) Increased caspase-2, calpain activations and decreased mitochondrial complex II activity in cells expressing exogenous huntingtin exon 1 containing CAG repeat in the pathogenic range. Cell Mol Neurobiol 27:11271145. CrossRef Medline

Malenka RC, Bear MF (2004) LTP and LTD: An embarrassment of riches. Neuron 44:5-21. CrossRef Medline

Manalan AS, Klee CB (1983) Activation of calcineurin by limited proteolysis. Proc Natl Acad Sci U S A 80:4291-4295. CrossRef Medline

Medler S, Chang ES, Mykles DL (2007) Muscle-specific calpain is localized in regions near motor endplates in differentiating lobster claw muscles. Comp Biochem Physiol A Mol Integr Physiol 148:591-598. CrossRef Medline

Mercier AJ, Atwood HL (1989) Long-term adaptation of a phasic extensor motoneurone in crayfish. J Exp Biol 145:9-22.

Millar AG, Zucker RS, Ellis-Davies GC, Charlton MP, Atwood HL (2005) Calcium sensitivity of neurotransmitter release differs at phasic and tonic synapses. J Neurosci 25:3113-3125. CrossRef Medline

Morales M, Colicos MA, Goda Y (2000) Actin-dependent regulation of neurotransmitter release at central synapse:a role for CAMKII. Neuron 27: 539-550. CrossRef Medline

Morishita W, Marie H, Malenka RC (2005) Distinct triggering and expression mechanisms underlie LTD of AMPA and NMDA synaptic responses. Nat Neurosci 8:1043-1050. CrossRef Medline

Msghina M, Millar AG, Charlton MP, Govind CK, Atwood HL (1999) Calcium entry related to active zones and differences in transmitter release at phasic and tonic synapses. J Neurosci 19:8419-8434. Medline
Mulkey RM, Malenka RC (1992) Mechanisms underlying induction of homosynaptic long-term depression in area CAl of the hippocampus. Neuron 9:967-975. CrossRef Medline

Mulkey RM, Herron CE, Malenka RC (1993) An essential role for protein phosphatases in hippocampal long-term depression. Science 261:10511055. CrossRef Medline

Mulkey RM, Endo S, Shenolikar S, Malenka RC (1994) Involvement of a calcineurin/inhibitor-1 phosphatase cascade in hippocampal long-term depression. Nature 369:486-488. CrossRef Medline

Munsch T, Deitmer JW (1995) Maintenance of Fura-2 fluorescence in glial cells and neurons of the leech central nervous system. J Neurosci Methods 57:195-204. CrossRef Medline

Negulescu PA, Reenstra WW, Machen TE (1989) Intracellular Ca requirements for stimulus-secretion coupling in parietal cell. Am J Physiol 256: C241-C251. Medline

Novgorodov SA, Chudakova DA, Wheeler BW, Bielawski J, Kindy MS, Obeid LM, Gudz TI (2011) Developmentally regulated ceramide synthase 6 increases mitochondrial $\mathrm{Ca}^{2+}$ loading capacity and promotes apoptosis. J Biol Chem 286:4644-4658. CrossRef Medline

Ouanounou A, Zhang L, Tymianski M, Charlton MP, Wallace MC, Carlen PL (1996) Accumulation and extrusion of permeant $\mathrm{Ca}^{2+}$ chelators in attenuation of synaptic transmission at hippocampal CA1 neurons. Neuroscience 75:99-109. CrossRef Medline

Samantaray S, Ray SK, Banik NL (2008) Calpain as a potential therapeutic target in Parkinson's disease. CNS Neurol Disord Drug Targets 7:305312. CrossRef Medline

Sanderson JL, Dell'Acqua ML (2011) AKAP signaling complexes in regulation of excitatory synaptic plasticity. Neuroscientist 17:321-336. CrossRef Medline

Sangenito LS, Ennes-Vidal V, Marinho FA, Da Mota FF, Santos AL, D’AvilaLevy CM, Branquinha MH (2009) Arrested growth of Trypanosoma cruzi by the calpain inhibitor MDL28170 and detection of calpain homologues in epimastigote forms. Parasitology 136:433-441. CrossRef Medline

Santana LF, Chase EG, Votaw VS, Nelson MT, Greven R (2002) Functional coupling of calcineurin and protein kinase $\mathrm{A}$ in mouse ventricular myocytes. J Physiol 544:57-69. CrossRef Medline

Schroer TA (1992) Motors for fast axonal transport. Curr Opin Neurobiol 2:618-621. CrossRef Medline

Schumacher PA, Siman RG, Fehlings MG (2000) Pretreatment with calpain inhibitor CEP-4143 inhibits calpain I activation and cytoskeletal degradation, improves neurological function, and enhances axonal survival after traumatic spinal cord injury. J Neurochem 74:1646-1655. CrossRef Medline

Serrano L, Díaz-Nido J, Wandosell F, Avila J (1987) Tubulin phosphorylation by casein kinase II is similar to that found in vivo. J Cell Biol 105: 1731-1739. CrossRef Medline

Shioda N, Moriguchi S, Shirasaki Y, Fukunaga K (2006) Generation of constitutively active calcineurin by calpain contributes to delayed neuronal death following mouse brain ischemia. J Neurochem 98:310-320. CrossRef Medline

Shioda N, Han F, Moriguchi S, Fukunaga K (2007) Constitutively active calcineurin mediates delayed neuronal death through Fas-ligand expression via activation of NFAT and FKHR transcriptional activities in mouse brain ischemia. J Neurochem 102:1506-1517. CrossRef Medline

Shtrahman M, Yeung C, Nauen DW, Bi GQ, Wu XL (2005) Probing vesicle dynamics in single hippocampal synapses. Biophys J 89:3615-3627. CrossRef Medline

Silverman-Gavrila LB, Charlton MP (2009) Calcineurin and cytoskeleton in low-frequency depression. J Neurochem 109:716-732. CrossRef Medline

Silverman-Gavrila LB, Orth PM, Charlton MP (2005) Phosphorylationdependent low-frequency depression at phasic synapses of a crayfish motoneuron. J Neurosci 25:3168-3180. CrossRef Medline

Stemmer PM, Klee CB (1994) Dual calcium ion regulation of calcineurin by calmodulin and calcineurin B. Biochemistry 33:6859-6866. CrossRef Medline

Suzuki K, Tsuji S, Kubota S, Kimura Y, Imahori K (1981) Limited autolysis of $\mathrm{Ca}^{2+}$-activated neutral protease (CANP) changes its sensitivity to $\mathrm{Ca}^{2+}$ ions. J Biochem 90:275-278. Medline

Tandan S, Wang Y, Wang TT, Jiang N, Hall DD, Hell JW, Luo X, Rothermel BA, Hill JA (2009) Physical and functional interaction between cal- 
cineurin and the cardiac L-type $\mathrm{Ca}^{2+}$ channel. Circ Res 105:51-60. CrossRef Medline

Tang Y, Schlumpberger T, Kim T, Lueker M, Zucker RS (2000) Effects of mobile buffers on facilitation: experimental and computational studies. Biophys J 78:2735-2751. CrossRef Medline

T'jampens D, Bailey J, Cook LJ, Constantin B, Vandekerckhove J, Gettemans J (1999) Physarum amoebae express a distinct fragmin-like actinbinding protein that controls in vitro phosphorylation of actin by the actin-fragmin kinase. Eur J Biochem 265:240-250. CrossRef Medline

To KCW, Church J, O'Connor TP (2008) Growth cone collapse stimulated by both calpain and Rho-mediated pathways. Neuroscience 153:645-653. CrossRef Medline

Tsien RY (1981) A non-disruptive technique for loading calcium buffers and indicators into cells. Nature 290:527-528. CrossRef Medline

Vandekerckhove J, Weber K (1978) The amino acid sequence of Physarum actin. Nature 276:720-721. CrossRef Medline

Van der Zee J, Mason RP, Eling TE (1989) The oxidation of the calcium probe quin 2 and its analogs by prostaglandin $\mathrm{H}$ synthase. Arch Biochem Biophys 271:64-71. CrossRef Medline

Van Harreveld A (1936) A physiological solution for freshwater crustaceans. Proc Soc Exp Biol Med 34:428 -432. CrossRef

von Reyn CR, Spaethling JM, Mesfin MN, Ma M, Neumar RW, Smith DH, Siman R, Meaney DF (2009) Calpain mediates proteolysis of the voltage-gated sodium channel alpha-subunit. J Neurosci 29:10350-10356. CrossRef Medline

Vyshedskiy A, Lin JW (2000) Presynaptic $\mathrm{Ca}^{2+}$ influx at the inhibitor of the crayfish neuromuscular junction: a photometric study at a high time resolution. J Neurophysiol 83:552-562. Medline

Wandosell F, Serrano L, Avila J (1987) Phosphorylation of alpha-tubulin carboxyl-terminal tyrosine prevents its incorporation into microtubules. J Biol Chem 262:8268-8273. Medline

Wang KK, Roufogalis BD, Villalobo A (1989) Characterization of the fragmented forms of calcineurin produced by calpain I. Biochem Cell Biol 67:703-711. CrossRef Medline

Wang KK, Nath R, Posner A, Raser KJ, Buroker-Kilgore M, Hajimohammadreza I, Probert A W Jr, Marcoux FW, Ye Q, Takano E, Hatanaka M, Maki M, Caner H, Collins JL, Fergus A, Lee KS, Lunney EA, Hays SJ, Yuen P (1996a) An alpha-mercaptoacrylic acid derivative is a selective nonpeptide cell-permeable calpain inhibitor and is neuroprotective. Proc Natl Acad Sci U S 93:6687-6692. CrossRef Medline

Wang XH, Zheng JQ, Poo MM (1996b) Effects of cytochalasin treatment on short-term synaptic plasticity at developing neuromuscular junctions in frogs. J Physiol 491:187-195. Medline

Wang Y, White MG, Akay C, Chodroff RA, Robinson J, Lindl KA, Dichter MA, Qian Y, Mao Z, Kolson DL, Jordan-Sciutto KL (2007) Activation of cyclin-dependent kinase 5 by calpains contributes to human immunodeficiency virus-induced neurotoxicity. J Neurochem 103:439-455. CrossRef Medline

Winslow JL, Duffy SN, Charlton MP (1994) Homosynaptic facilitation of transmitter release in crayfish is not affected by mobile calcium chelators: implications for the residual ionized calcium hypothesis from electrophysiological and computational analyses. J Neurophysiol 72:1769-1793. Medline

Wu HY, Lynch DR (2006) Calpain and synaptic function. Mol Neurobiol 33:215-236. CrossRef Medline

Wu HY, Tomizawa K, Oda Y, Wei FY, Lu YF, Matsushita M, Li ST, Moriwaki A, Matsui H (2004) Critical role of calpain-mediated cleavage of calcineurin in excitotoxic neurodegeneration. J Biol Chem 279:4929-4940. CrossRef Medline

Wu Y, Liang S, Oda Y, Ohmori I, Nishiki T, Takei K, Matsui H, Tomizawa K (2007) Truncations of amphiphysin I by calpain inhibit vesicle endocytosis during neural hyperexcitation. EMBO J 26:2981-2990. CrossRef Medline

Yasuda H, Higashi H, Kudo Y, Inoue T, Hata Y, Mikoshiba K, Tsumoto T (2003) Imaging of calcineurin activated by long-term depressioninducing synaptic inputs in living neurons of rat visual cortex. Eur J Neurosci 17:287-297. CrossRef Medline

Yoshimura Y, Aoi C, Yamauchi T (2000) Investigation of protein substrates of $\mathrm{Ca}^{2+} /$ calmodulin-dependent protein kinase II translocated to the postsynaptic density. Brain Res Mol Brain Res 81:118-128. CrossRef Medline

Yu X, Mykles DL (2003) Cloning of a muscle-specific calpain from the American lobster Homarus americanus: expression associated with muscle atrophy and restoration during moulting. J Exp Biol 206:561-575. CrossRef Medline

Zamir O, Charlton MP (2006) Cholesterol and synaptic transmitter release at crayfish neuromuscular junctions. J Physiol 571:83-99. CrossRef Medline

Zar JH (1996) Biostatistical analysis, Ed 3, p 88. Upper Saddle River, NJ: Prentice-Hall.

Zhong N, Zucker RS (2004) Roles of $\mathrm{Ca}^{2+}$, hyperpolarization and cyclic nucleotide-activated channel activation, and actin in temporal synaptic tagging. J Neurosci 24:4205-4212. CrossRef Medline

Zhu M, Li F, Tong X, He J, Hong A, Rakhmanova V-AnaSpec, Inc (2009) A novel fluorimetric assay for detection of calpain activity with FRET-based substrate. Paper (753 B700) presented at the 49th Annual Meeting of the American Society for Cell Biology, San Diego, December 5-9.

Zucker RS, Regehr WG (2002) Short-term synaptic plasticity. Annu Rev Physiol 64:355-405. CrossRef Medline 